\title{
Optical Investigation of Sooting Propensity of $n$-Dodecane Pilot/Lean-Premixed Methane Dual-Fuel Combustion in a Rapid Compression-Expansion Machine
}

\author{
Aleš Srna Paul Scherrer Institute \\ Gilles Bruneaux IFP Energies nouvelles, Institut Carnot IFPEN TE
}

Beat von Rotz and Rolf Bombach Paul Scherrer Institute

Kai Herrmann University of Applied Sciences FHNW

Konstantinos Boulouchos Swiss Federal Institute of Technology

Citation: Srna, A., Bruneaux, G., von Rotz, B., Bombach, R. et al., "Optical Investigation of Sooting Propensity of $n$-Dodecane Pilot/LeanPremixed Methane Dual-Fuel Combustion in a Rapid Compression-Expansion Machine," SAE Technical Paper 2018-01-0258, 2018, doi:10.4271/2018-01-0258.

\section{Abstract}

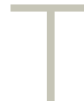

he sooting propensity of dual-fuel combustion with $n$-dodecane pilot injection in a lean-premixed methane-air charge has been investigated using an optically accessible Rapid Compression-Expansion Machine to achieve engine relevant pressure and temperature conditions at start of pilot injection. A Diesel injector with a $100 \mu \mathrm{m}$ single-hole coaxial nozzle, mounted at the cylinder periphery, has been employed to admit the pilot fuel.

The aim of this study was to enhance the fundamental understanding of soot formation and oxidation processes of $n$-dodecane in presence of methane in the air charge by parametric variation of methane equivalence ratio, charge temperature and pilot fuel injection duration. The influence of methane on ignition delay and flame extent of the pilot fuel jet has been determined by simultaneous $\mathrm{OH}^{*}$ chemiluminescence and Schlieren imaging. The sooting behavior of the flame has been characterized using the 2D-DBI imaging methodology. The apparent soot black-body temperature has been measured 1D-resolved along the injector axis by applying an imaging spectrograph.

Addition of methane into the air charge considerably prolongs the ignition delay with an increasing effect under less reactive conditions and with higher methane equivalence ratios. Therefore, the influence of methane on the formation of soot is two-fold: in case of short pilot injection, the presence of methane was found to decrease the soot formation due to the leaner pilot fuel mixture at time of ignition. For longer pilot fuel injections, methane enhances the soot production by decreasing oxygen availability and introducing additional carbon. In all cases, methane strongly defers the oxidation of soot due to the lower availability of oxygen.

\section{Introduction}

ean-premixed burning natural gas engines offer a potentially attractive short to midterm solution for increasing engine efficiency while mitigating the pollutant emissions without an extensive exhaust gas aftertreatment system. At the same time natural gas as fuel has advantages of high knocking resistance, highest $\mathrm{H} / \mathrm{C}$ ratio among hydrocarbons and low sooting tendency. However, lean premixed methane mixtures are difficult to ignite and oxidize, leading to unstable engine running and high UHC emissions [1]. Dual-fuel engines (in gas mode) utilizing the pilot injection of Diesel fuel as a high-energy ignition source are extensively researched as a combustion technology which can ensure reliable ignition while maintaining low pollutant emissions $[2, \underline{3}, 4]$.
Various aspects of dual-fuel combustion (Diesel pilot ignited) have been studied up to date in complete engines $[\underline{5}, \underline{6}, \underline{7}]$, single cylinder engines $[\underline{8}, \underline{9}, \underline{10}, \underline{11}, \underline{12}, \underline{13}, \underline{14}, \underline{15}]$, optical engines $[15,16,17, \underline{18}]$ as well as rapid compression machines $[19,20,21]$. The approach of most of the engine experiments was to substitute part of the Diesel fuel (by reducing the injection duration) with premixed methane while monitoring the exhaust emissions and heat release rate. Significant reduction of the engine $\mathrm{NO}_{\mathrm{x}}$ emissions at low and moderate loads has been reported together with reduced peak pressure rise and prolonged combustion duration $[\underline{5}, \underline{6}, \underline{8}, \underline{9}$, $\underline{10}, \underline{11}, \underline{12}$. The drawback of the dual-fuel engines (in gas mode) is most obviously a significant increase of the UHC emissions which are more than two orders of magnitude higher than 
when engine runs in Diesel mode $[\underline{8}, \underline{11}, \underline{12}]$. The UHC emissions values can range up to $20^{\prime} 000 \mathrm{ppm}$ [7] and consist up to $90 \%$ of methane [6]. Increasing the premixed fuel equivalence ratio or the pilot fuel portion promotes complete combustion (decrease in UHC) [6] but there is an apparent tradeoff between the UHC, soot and $\mathrm{NO}_{\mathrm{x}}$ emissions $[\underline{6}, \underline{8}, \underline{11}, \underline{12}]$. Nevertheless, there is a general consent that by precise control of the engine operating parameters both improved engine efficiency and low emissions of $\mathrm{NO}_{\mathrm{x}}$ and soot can be achieved in the dual-fuel operation over the whole engine operating map while limiting the UHC emissions to a moderate level $[\underline{4}, \underline{22}]$.

Several publications report considerable decrease of particulate matter emission by the substitution of Diesel fuel with premixed natural gas or methane $[\underline{10}, \underline{11}, \underline{18}]$. This can be explained by the decreased portion of the fuel burnt in the diffusion combustion and by the absence of $\mathrm{C}-\mathrm{C}$ bonds as well as sulfur in the natural gas fuel. However, under some operating conditions the tradeoff of efficiency, $\mathrm{UHC}, \mathrm{NO}_{\mathrm{x}}$ and soot does not allow for engine operation in smokeless mode [6]. Fundamental understanding of the sooting propensity of dual-fuel combustion can therefore considerably aid the engine design to minimize emissions of soot over the entire operation map. In this respect, engine research has mostly focused on the investigation of dual-fuel exhaust gas soot quantity $[10,11]$ as well as morphology [18] under different operating conditions. Zhang et al. [18] showed a tendency of reducing soot emissions and its particulate size for dual-fuel combustion in comparison to the conventional Diesel operation mode.

Dual-fuel combustion experimental research in optically accessible test rigs mostly focused on the influence of methane on ignition delay $[\underline{19}, \underline{20}, \underline{21}]$, flame spreading rate $[\underline{17}, \underline{19}, \underline{20}$, $\underline{21}, \underline{23}]$ and shape of the combustion front [17]. Only a few optical studies investigating in-cylinder dual-fuel combustion sooting propensity have been published up to date with the available data mostly limited to natural luminosity imaging $[\underline{15}, \underline{23}]$ and two-color pyrometry [24]. On the other hand, the optical diagnostics of soot in Diesel sprays has significantly progressed in the recent years based on the research performed in constant volume chambers and optical engines. The considered optical diagnostics range from soot natural luminosity imaging [25], laser induced incandescence [26], multi-color diffuse back illumination [27, 28], and multi-color pyrometry [29] up to soot morphology detection by sampling and subsequent imaging using the electron transmission microscope [30].

The aim of the present study is to understand the influence of premixed methane on the Diesel pilot soot production and oxidation by application of selected optical diagnostic techniques to detect the soot optical density (diffuse back illumination) and soot temperature (1D spectroscopy). The measurement matrix consists of variation of the injection duration, temperature at start of injection $\left(\mathrm{T}_{\mathrm{SOI}}\right)$ and premixed methane equivalence ratio, resulting in mildly to moderately sooting conditions. The Diesel engine characteristic range of the $\mathrm{T}_{\mathrm{SOI}}(770 \mathrm{~K}-1000 \mathrm{~K})$ has been selected and the pilotinjections in compressed air provided reference cases.

The publication is structured as follows: The subsequent section describes the experimental apparatus, the optical diagnostic setup and the measurement matrix including a discussion of the experimental uncertainties. In the results section, the influence of methane on sooting propensity of dual-fuel combustion is presented. The discussion focuses on different aspects of $n$-dodecane spray soot formation and oxidation in the presence of methane and is facilitated using the $1 \mathrm{D}$ transient spray model of Pastor and coworkers [31].

\section{Experimental Setup}

\section{Rapid Compression-Expansion Machine}

In the present study, a Rapid Compression Expansion Machine (RCEM) has been utilized to compress the homogeneous methane/air charge in order to achieve engine relevant conditions at the time of pilot fuel injection. The RCEM is a generic free-floating piston test rig (bore: $84 \mathrm{~mm}$, variable stroke: $120-249 \mathrm{~mm}$ ) with optical accessibility through piston and cylinder head windows. A brief description of the machine and its operation principle is provided here, while further descriptions are available in $[\underline{20}, \underline{32}, \underline{33}]$.

A sectional view of the RCEM and its operating principle is presented in Figure 1. The machine operates in a single cycle mode (compression and partial expansion). The drive energy for the piston motion is provided through the compressed air charge acting on a system of hydraulically coupled working piston and mass-balance piston, which move in the opposite directions to enable vibration free operation. Due to the absence of mechanical piston coupling to a flywheel, the piston acceleration is governed by the pressure difference between driving volume and combustion chamber. The subsequent piston motion results in a pendulum-like swing with a fast ejection of the piston towards the top dead center (TDC). The piston decelerates as the pressure in the combustion chamber builds up and swings back towards the equilibrium position. Within the time interval between $-4 \mathrm{~ms}$ and $4 \mathrm{~ms}$ around TDC the piston motion closely follows the piston stroke of an engine running at $1200 \mathrm{rpm}$ [19].

FIGURE 1 Sectional view of the RCEM and schematic of the operation principle of the oil-coupled free-floating working and balancing piston. Adapted from [33].

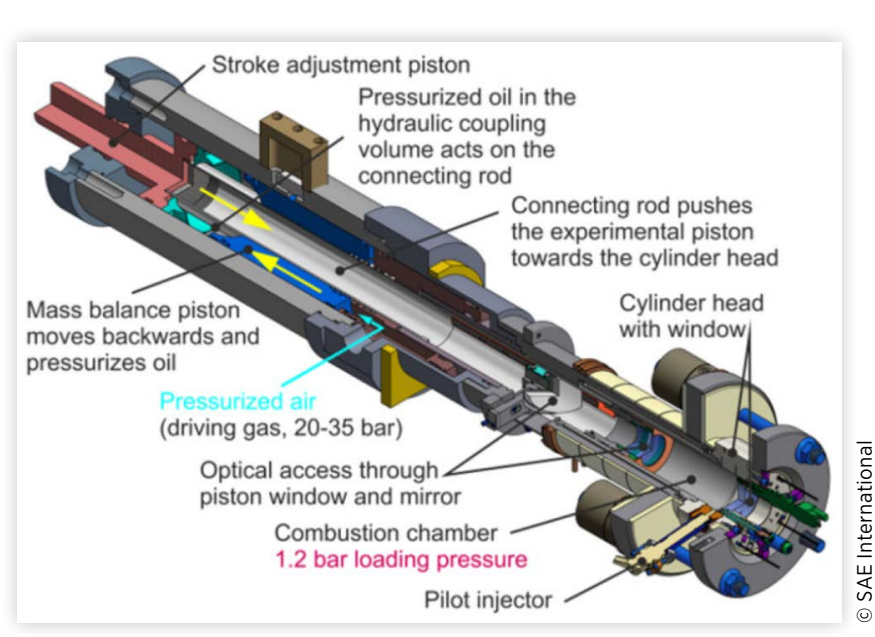

(c) 2018 SAE International. All Rights Reserved. 
FIGURE 2 RCEM combustion chamber geometry. Dimensions in $\mathrm{mm}$.

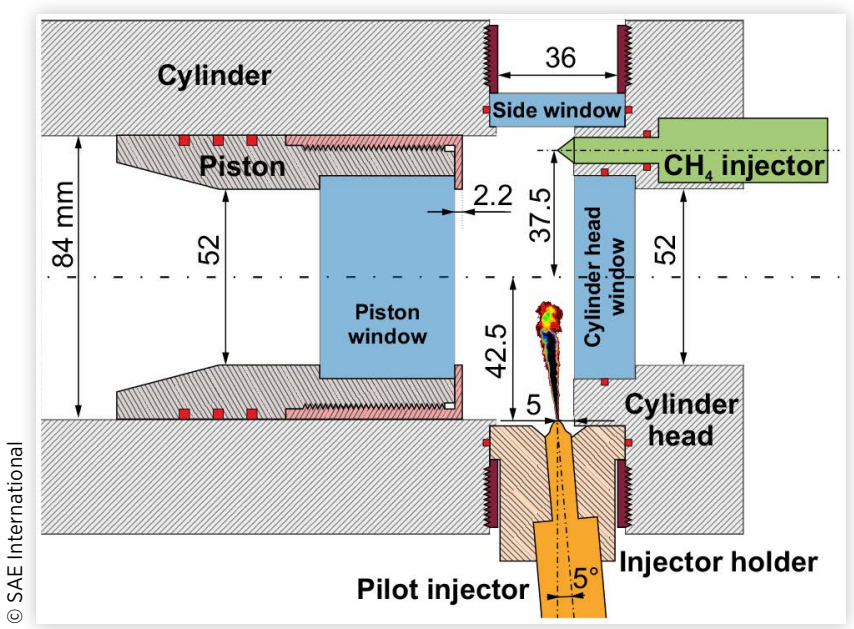

The RCEM combustion chamber has a cylindrical geometry with a flat cylinder head and virtually flat piston (2.2 mm piston bowl) (Figure 2). A standard common-rail Diesel injector body (Bosch CRI2-16) equipped with a custom $100 \mu \mathrm{m}$ diameter single-hole conical coaxial nozzle tip (KS 1.5 , discharge coefficient $C_{d}=0.80$ ) has been used to admit the pilot fuel. The injector was mounted on the cylinder periphery at $5^{\circ}$ axis inclination towards piston. The nozzle orifice position was located at a distance of $5 \mathrm{~mm}$ from the cylinder head and $42.5 \mathrm{~mm}$ from the cylinder axis.

The methane/air mixture has been conditioned in the combustion chamber by direct injection of methane at time of $4.0 \mathrm{~s} \pm 0.2 \mathrm{~s}$ prior to the rapid compression and after the air charge filling process has been completed. An outward opening hollow-cone gasoline injector (Continental) has been employed to deliver methane $e^{1}$. High injection pressure of methane ( 60 bar) in combination with a long mixing time allowed for the formation of a homogeneous mixture. The methane distribution in the cylinder prior to the compression has been investigated employing the tracer-LIF technique with anisole. The tests have been performed in a separate setup consisting of a sealed heated quartz cylinder which reproduces the RCEM bottom dead center (BDC) geometry and wherein comparable thermodynamic conditions are present. The volume-average standard deviation of the methane concentration from the homogeneous mixture was $\sigma=0.067$. Further details regarding characterization of the methane mixture prior to compression are given in Appendix A. The injector mass flow has been characterized by measuring the pressure rise in the RCEM combustion chamber during the injection. The quantity of injected methane has been controlled by adjusting the injector opening time (22-39 ms).

The temperature of the methane/air charge in the BDC is precisely controlled by heating the cylinder liner and cylinder head with a multi-zone electrical heating system.

${ }^{1}$ Commercial high-pressure gas injectors were found to exhibit a constant small leak of fuel into the combustion chamber, which is prohibitive in the RCEM due to the low repetition rate (5 min per repetition).
TABLE 1 General specifications of the RCEM.

\begin{tabular}{|c|c|}
\hline Cylinder bore & $84 \mathrm{~mm}$ \\
\hline Stroke & Adjustable, $120-249 \mathrm{~mm}$ \\
\hline Displaced volume & $0.67-1.38 \mathrm{dm}^{3}$ \\
\hline $\begin{array}{l}\text { Realizable compression } \\
\text { ratio }\end{array}$ & $5-25$ \\
\hline Charge intake pressure & $1.1-2$ bar \\
\hline Cylinder head geometry & flat \\
\hline Piston bowl geometry & Top hat, $\varnothing 52 \mathrm{~mm} \times 2.2 \mathrm{~mm}$ \\
\hline $\begin{array}{l}\text { Cylinder liner and head } \\
\text { heating }\end{array}$ & Multi-zone electric, up to $450 \mathrm{~K}$ \\
\hline Optical access & $\begin{array}{l}\text { Piston window, } \varnothing 52 \mathrm{~mm} \\
\text { Cylinder head window } \varnothing 52 \mathrm{~mm} \\
\text { Lateral window } \varnothing 36 \mathrm{~mm} \text { (not used) }\end{array}$ \\
\hline Pilot fuel injection & $\begin{array}{l}\text { Bosch CRI2-16 injector body } \\
\varnothing 100 \mu \mathrm{m} \mathrm{KS1.5} \text { single hole coaxial } \\
\text { nozzle }\end{array}$ \\
\hline Methane injector & $\begin{array}{l}\text { Continental outwards opening } \\
\text { hollow-cone nozzle }\end{array}$ \\
\hline
\end{tabular}

The homogeneity of the mixture temperature in this RCEM has been investigated in previous studies [20], reporting temperature homogeneity better that $3 \mathrm{~K}$ before compression. PIV investigations of the RCEM flow field reported quiescent conditions throughout the cycle [33].

The RCEM instrumentation includes precise recording of the piston position (resolution $0.02 \mathrm{~mm}$ ) and cylinder pressure (flush-mounted piezoelectric transducer, Kistler $7061 \mathrm{~B}, 0-250 \mathrm{bar}$ ) at rate of $100 \mathrm{kHz}$. The piezoelectric sensor is pegged using a precise absolute pressure transducer (Kistler 4075A10, 0-10 bar) in a fast-switching adapter (Kistler 741A). General RCEM specifications are given in Table 1.

\section{Operating Conditions}

In this study the RCEM has been operated at the maximal BDC displacement setting $\left(1.38 \mathrm{dm}^{3}\right.$ displacement, $249 \mathrm{~mm}$ BDC clearance to the cylinder head) to have a sufficient TDC clearance for minimizing the pilot spray interaction with walls.

The operation strategy of the RCEM was selected to ensure high repeatability of the conditions at start of injection (SOI). The free-floating piston design of the machine results in an inherently uncertain piston motion, which will be influenced by the combustion pressure rise, variation in the driving gas pressure and friction of the piston motion. Preparatory studies have been performed to assess this piston motion variability: the results assure a high repeatability up to a time of $2 \mathrm{~ms}$ before the TDC. Later in the cycle the variability slightly increases. Figure 3 shows the average piston position, pressure trace and the $1 \times \sigma$ cyclic variability (one standard deviation) of both traces based on 100 cycles. Piston motion of an engine running at 1200RPM with the same stroke (connecting rod ratio 1.64) is plotted for reference.

Based on this analysis, a high compression ratio $(C R=20)$ operation strategy with early pilot injection has been selected. 
FIGURE 3 Piston position and in-cylinder pressure trace averaged over 100 non-reactive cycles. $1 \times \sigma$ variability of both traces is demonstrated by the shaded regions. Stroke of an engine running at 1200 RPM is shown with the gray dashed line. Injection timing is marked with a green line.

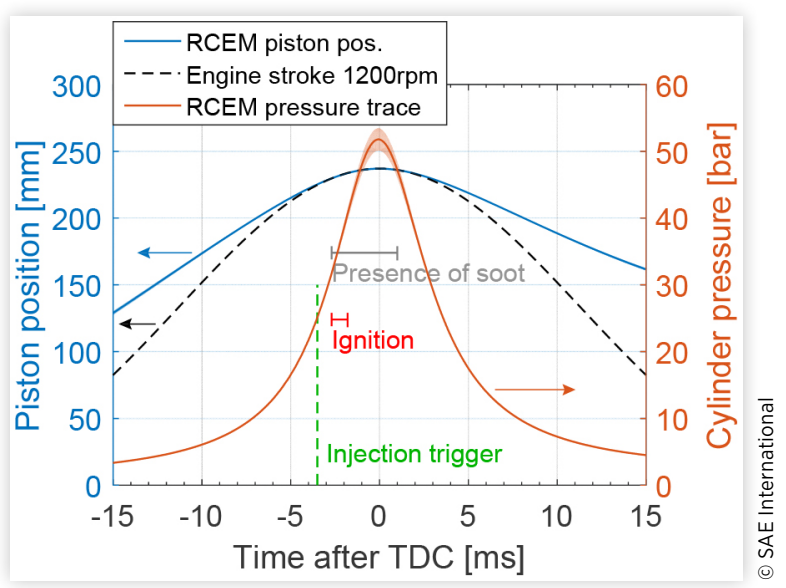

Pilot fuel is injected approximately $3.5 \mathrm{~ms}$ before TDC. Therefore, the auto-ignition of the pilot fuel takes place during the time frame with low RCEM cycle variability. Furthermore, the high compression ratio setting extends the operation limit of the RCEM in terms of the total heat release in the cycle by decelerating the reverse piston motion towards BDC. If the total energy released in the cycle exceeds this limit, the piston collides with the stroke setting piston in the BDC, potentially resulting in damage of the sealing between both pistons.

The pilot fuel injection has been triggered based on the pressure signal. Two thresholds of 25 bar and 45 bar cylinder pressures have been selected. The bulk temperature at the SOI has been estimated using a thermodynamic model accounting for compression, wall heat losses, crevice volumes and piston rings blow-by. The temperatures at the start of injection $\left(\mathrm{T}_{\mathrm{SOI}}\right)$ at the 25 bar threshold were reckoned at $775 \mathrm{~K}, 810 \mathrm{~K}$ and $850 \mathrm{~K}$ with cylinder wall temperatures of $343 \mathrm{~K}, 363 \mathrm{~K}$ and $383 \mathrm{~K}$, respectively. These conditions are considered to be low to moderately sooting. The second threshold ( 45 bar) corresponds to $\mathrm{T}_{\mathrm{SOI}}=1000 \mathrm{~K}$ (wall temperature $383 \mathrm{~K}$ ) which offers a comparison under highly sooting conditions. The compression ratio has been slightly increased to $\mathrm{CR}=22$. An overview of the investigated conditions is presented in Table 2.

Combustion chamber charge consisted of air $\left(21 \% \mathrm{O}_{2}\right)$ mixed with methane. The $\mathrm{T}_{\mathrm{SOI}}$ change due to the high methane specific heat ratio was estimated to be $6 \mathrm{~K}$ for the highest considered methane concentration - neglected consequently in the further analysis.

The injection rate profile of the pilot injector has been characterized for the selected rail pressures and energizing times using a "Bosch tube" type injection rate analyzer. The measured steady fuel injection rate at 30 bar tube pressure was $2.43 \mathrm{mg} / \mathrm{ms}$ and $3.33 \mathrm{mg} / \mathrm{ms}$ for 600 bar and 1000 bar rail pressure, respectively. The duration of the injector opening and closing transient was $140 \mu \mathrm{s}$ (600 bar) and $110 \mu \mathrm{s}$ (1000 bar), respectively.
TABLE 2 Overview of the operating conditions. Values in the middle column relate to trigger pressure threshold of 25 bar (dataset 1, 770-850 $\mathrm{K} \mathrm{T}_{\text {sol }}$ ), conditions in the right column relate to $\mathrm{P}_{\mathrm{SOI}}=45$ bar (dataset $2,1000 \mathrm{~K} \mathrm{~T}_{\mathrm{SOI}}$ )

\begin{tabular}{|c|c|c|}
\hline & $\begin{array}{l}\text { Dataset 1: } \\
\mathrm{T}_{\mathrm{sol}}=\mathbf{7 7 0 - 8 5 0 \mathrm { K }}\end{array}$ & $\begin{array}{l}\text { Dataset 2: } \\
\mathrm{T}_{\text {SOI }}=1000 \mathrm{~K}\end{array}$ \\
\hline BDC displacement & $1.38 \mathrm{dm}^{3}$ & \\
\hline Charge intake pressure & 1.2 bar & \\
\hline Stroke & $236.5 \mathrm{~mm} \pm 1 \mathrm{~mm}$ & $238.2 \mathrm{~mm} \pm 1 \mathrm{~mm}$ \\
\hline Compression ratio & 20 & 22 \\
\hline BDC temperature & $343 \mathrm{~K}, 363 \mathrm{~K}, 383 \mathrm{~K}$ & $383 \mathrm{~K}$ \\
\hline Pressure at $\mathrm{SOI}\left(\mathrm{P}_{\mathrm{SOI}}\right)$ & 25 bar & 45 bar \\
\hline $\begin{array}{l}\text { Temperature at SOI } \\
\left(\mathrm{T}_{\mathrm{SOI}}\right)\end{array}$ & $770 \mathrm{~K}, 810 \mathrm{~K}, 850 \mathrm{~K}$ & $1000 \mathrm{~K}$ \\
\hline $\begin{array}{l}\text { Pilot injector } \\
\text { energizing time (ET) }\end{array}$ & $\begin{array}{l}400 \mu \mathrm{s}, 500 \mu \mathrm{s}, \\
700 \mu \mathrm{s}\end{array}$ & $300 \mu \mathrm{s}, 700 \mu \mathrm{s}$ \\
\hline Pilot injection duration & $\begin{array}{l}0.58 \mathrm{~ms}, 0.77 \mathrm{~ms} \text {, } \\
1.21 \mathrm{~ms}\end{array}$ & $0.40 \mathrm{~ms}, 1.34 \mathrm{~ms}$ \\
\hline Pilot injection pressure & 600 bar & 1000 bar \\
\hline $\begin{array}{l}\text { Methane/air mixture } \\
\text { equivalence ratio } \\
\left(\varphi_{\mathrm{CH} 4}\right)\end{array}$ & $0,0.33,0.59$ & $0,0.33,0.48$ \\
\hline
\end{tabular}

\section{Optical Diagnostics}

Two optical diagnostic setups have been applied at the RCEM. To detect the pilot spray penetration, ignition delay and flame spreading simultaneous Schlieren and $\mathrm{OH}^{\star}$ imaging have been used. The second experimental setup has been employed to detect soot optical thickness and 1D-resolved soot temperature based on the DBI imaging and spectrally resolved soot luminosity acquisitions. Both setups and the data processing approach are presented subsequently.

\section{Schlieren and $\mathrm{OH}^{*}$ Chemiluminescence Imaging} The layout of the Schlieren and $\mathrm{OH}^{*}$ imaging setup is shown in Figure 4 . Both methods were applied along the same optical axis through the $\varnothing 52 \mathrm{~mm}$ piston and cylinder head windows. A dichroic mirror has been used to separate the Schlieren beam from the $\mathrm{OH}^{\star}$ signal. All devices were synchronized using a programmable timing unit (LaVision).

FIGURE 4 Optical setup for simultaneous Schlieren and $\mathrm{OH}^{*}$ chemiluminescence imaging.

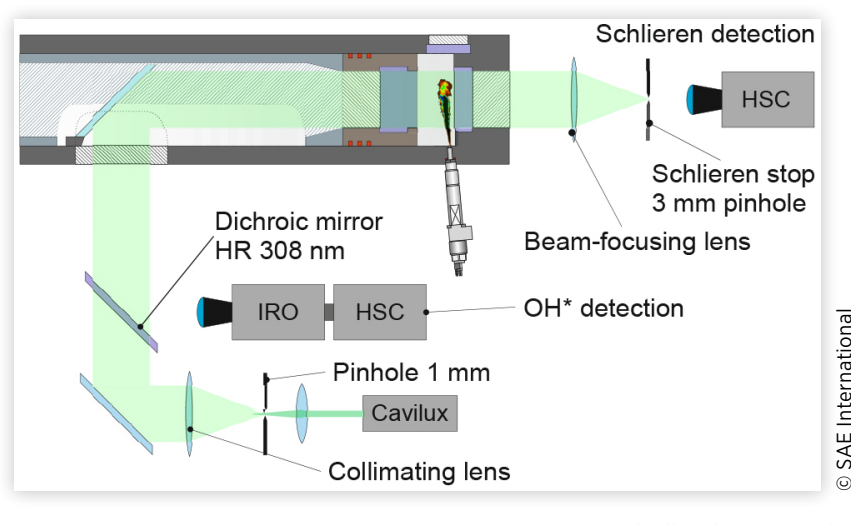


Schlieren. Schlieren imaging has been performed at frame rate of $80 \mathrm{kHz}$ with a projected pixel size of $0.16 \mathrm{~mm} /$ pixel. A fiber-coupled pulsed laser diode array (Cavilux Smart, wavelength $690 \pm 10 \mathrm{~nm}, 10 \mathrm{~ns}$ pulse duration, $440 \mathrm{~W}$ output) illuminating a close-coupled diffusor plate and a $1 \mathrm{~mm}$ diameter pinhole has been used to generate a point light source. The light has been collimated using a $100 \mathrm{~mm}$ diameter $\mathrm{f} / 4$ achromatic lens and directed along the cylinder axis through the combustion chamber. The collimated beam has been refocused using another achromatic lens of the same type. An aperture diameter of $3 \mathrm{~mm}$ in the lens focal point has been used as Schlieren stop. After passing the Schlieren stop the light was recorded with a high-speed camera (Photron Fastcam SA-X2) equipped with a Nikkor $50 \mathrm{~mm}$ f/1.4 lens to achieve the desired image scale. The camera exposure time was $1 \mu$ s; the lens was equipped with a $690 \mathrm{~nm}$ bandpass filter to suppress the flame luminosity. The aperture sizes of $1 \mathrm{~mm}$ and $3 \mathrm{~mm}$ were selected to achieve a sufficient contrast of the Schlieren images by an empirical approach, as described in [34], resulting in similar beam-divergence tolerance of the system as in other comparable studies [19, $\underline{35}$. Due to hardware obstructions between the piston and mirror the region closer than $22 \mathrm{~mm}$ to the injector orifice is not visibly accessible.

$\mathrm{OH}^{*}$ Chemiluminescence. Filtered flame emission in the spectral range of chemically excited hydroxyl $\left(\mathrm{OH}^{*}\right.$ radicals $)$ has been acquired at a frame rate of $40 \mathrm{kHz}$ using an image intensifier (LaVision HS-IRO, S20 photocathode), relay-optics coupled to a high-speed camera (Photron FastCam SA1.1). The intensifier was equipped with a Sodern UV lens (Cerco $100 \mathrm{~mm}$ $\mathrm{f} / 2.8$ ) and a bandpass filter ( $313 \mathrm{~nm} \pm 13 \mathrm{~nm}$ ). The resulting resolution was $0.18 \mathrm{~mm} /$ pixel. The intensifier gate was set to $20 \mu$ s and the gain was adapted to the brightness of the flame emission under different conditions (9-45 counts/photoelectron). The UV radiation has been separated from the Schlieren beam using a $308 \mathrm{~nm} 45^{\circ}$ laser mirror (100 mm diameter, $95 \%$ reflection in range $295-325 \mathrm{~nm}, 87 \%$ transmission at $690 \mathrm{~nm}$ ).

Diffuse Back-Illumination Imaging and 1D Spectroscopy The experimental setup for simultaneous diffuse back-illumination (DBI) imaging and 1D-spectroscopy at the RCEM facility is illustrated in Figure 5.

Diffuse Back-Illumination Setup. The DBI setup sketched in Figure 5 closely resembles the recently proposed improved DBI setup of Westlye et al. [28]. The diffuse back illumination of the soot cloud was realized by directing the collimated output of the fiber coupled laser diode (same unit as used for Schlieren) on an engineered diffusor (RPC Photonics, $10^{\circ}$ scattering cone angle) ensuring homogeneous diffuse illumination across the whole RCEM window. The diffusor has been placed at a close distance to the combustion chamber $(60 \mathrm{~mm})$ as recommended in [28]. On the detection side, the light from the RCEM combustion chamber was split using a dichroic mirror $(50 \%$ reflection in the range of $300 \mathrm{~nm}$ to $550 \mathrm{~nm}$ and high transmission at other wavelengths) ${ }^{2}$. The laser diode light

\footnotetext{
${ }^{2}$ The beamsplitter shows some drawbacks for this application. No stock optical element of sufficient size with more appropriate properties could be identified at the time.
}

FIGURE 5 Optical setup for simultaneous DBI imaging and 1D flame spectroscopy acquisition.

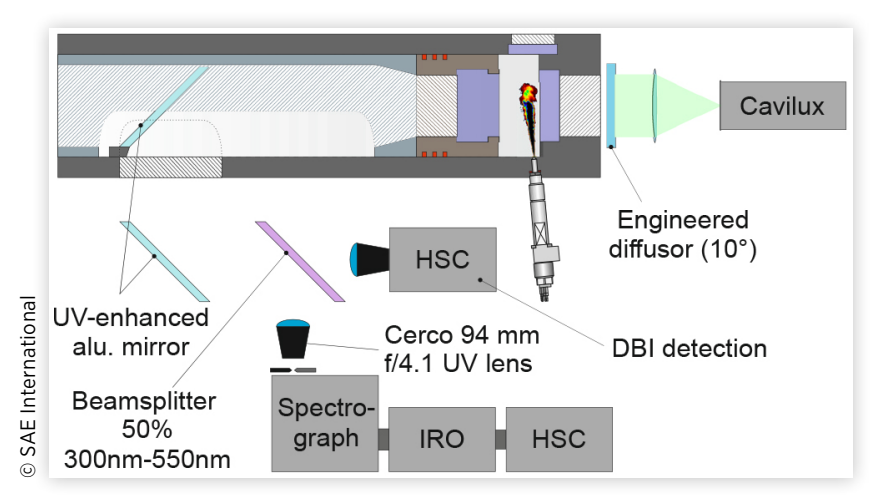

emission at $690 \mathrm{~nm}$ (100 ns pulse length) was partially transmitted through the dichroic mirror and detected with a high speed camera (Photron Fastcam SA-X2) equipped with a photographic lens and a bandpass filter to block the soot luminosity (Sigma $105 \mathrm{~mm} \mathrm{f} / 2.8$ lens, bandpass filter $690 \mathrm{~nm}$ FWHM $10 \mathrm{~nm}$ ). The DBI images were acquired with a frame rate of $10 \mathrm{kHz}$ and projected pixel size of $0.12 \mathrm{~mm} /$ pixel. Due to geometrical limitations of the RCEM it was not possible to position the detector closer than $0.7 \mathrm{~m}$ to the combustion chamber.

The DBI image processing followed the methodology proposed by the Engine Combustion Network [36]. In order to remove the interference of the soot luminosity on the absorption detection, the camera frame rate $(20 \mathrm{kHz})$ was set at twice the pulse rate of the laser diode illumination. Hence, every second image was not illuminated by the light source and therefore recorded the soot incandescence only. An average of the preceding and following image was subtracted from each illuminated image. The resulting image was then normalized by the bright-field image (obtained from the five images of the series acquired before SOI). Finally, the KL factor was calculated based on the light absorption.

Analysis of the DBI noise and Schlieren interference has been performed based on non-sooting reactive and non-reactive acquisitions in order to assess the lower detection limit of this DBI setup. Over the whole image field, except over the $4 \mathrm{~mm}$ wide boundary at the window edge, the Schlieren effects were well suppressed. The lower detection limit was estimated at $\mathrm{KL}=0.04$.

1D Flame Emission Spectroscopy Setup. A part of the soot incandescence and flame luminosity was reflected by the dichroic beamsplitter towards the spectrograph and projected on the spectrograph slit with a Sodern UV objective (Cerco $94 \mathrm{~mm} \mathrm{f} / 4.1$ ). The application of imaging spectrograph (Acton Sp-300i, grating 300 lines $/ \mathrm{mm}$ blazed for $500 \mathrm{~nm}$ ) enabled 1D resolution of the spectrum along the slit. The spectrally dispersed light was detected with an intensified high-speed camera system (LaVision HS-IRO coupled with Photron FastCam SA1.1) operated at a frame rate of $20 \mathrm{kHz}$ (intensifier gate $45 \mu \mathrm{s}$, gain 7-20 counts/photoelectron). The wavelength range between $250 \mathrm{~nm}$ and $610 \mathrm{~nm}$ was acquired. The spectral resolution of the system was $2 \mathrm{~nm}$ (slit width $40 \mu \mathrm{m}$ ) and the projected line height $0.20 \mathrm{~mm} /$ pixel row. Actual projected 
resolution along the slit was only around $1 \mathrm{~mm}$ due to spectrograph aberrations. The field of view of the $1 \mathrm{D}$ spectroscopy was set to spectrally resolve the flame emission and soot luminosity in one dimension along the fuel-injector axis.

Spectroscopy Data Processing and Uncertainty Assessment. Soot is a colored body emitting close to the flame temperature where most of the luminosity is expected in the NIR and visible wavelengths. Under hot conditions the soot black-body luminosity can extend also towards the near $\mathrm{UV}$ region and, for example, cause interference with the $\mathrm{OH}^{*}$ acquisition. We have selected a wavelength range of 250-610 $\mathrm{nm}$ to assess both the level of soot interference on $\mathrm{OH}^{*}$ imaging and determine the soot black-body temperature. The long-wavelength range of acquisition was limited by the $\mathrm{OH}^{*}$ signal $2^{\text {nd }}$ order diffraction overlapping the soot luminosity in the $620 \mathrm{~nm}$ range and the DBI illumination at $690 \mathrm{~nm}$; it is undesired that this strong radiation hits the intensifier photocathode.

The spectroscopic images were further processed to yield information about the soot temperature. The spectrum acquired by the setup depends on the quantum efficiency and spectral dependence of all elements in the spectral acquisition chain. Common approach to correct the system spectral sensitivity is based on calibration using a diffuse light source with a known spectral dependence. Since no such light source with a sufficient spectral intensity in the near UV was available, the calibration was performed based on the spectral properties of each element in the measurement system (see Appendix B).

The correction approach of the raw emission spectra is demonstrated in Figure 6. The raw spectra are obtained by averaging ten repetitions of the experiment and across 10 pixels along the injector axis $(2 \mathrm{~mm}$ resolution along the injector axis). These raw spectra are corrected for the system efficiency by division with the spectrally dependent system sensitivity. After the correction, spectrum closely resembles a black-body radiation as long as soot radiation is the dominant source of luminosity. In order to estimate the soot temperature, a soot-emissivity corrected Planck's law curve is fitted to the corrected spectrum in the wavelength range of $470 \mathrm{~nm}$

FIGURE 6 1D-spectroscopy processing approach: Raw and corrected spectrum (sp.) of a sooting combustion (left). The dashed lines represent the Planck fit of the black-body luminosity and the spline fit of the chemiluminescence intensity. Raw and corrected spectrum from a non-sooting combustion event (right).

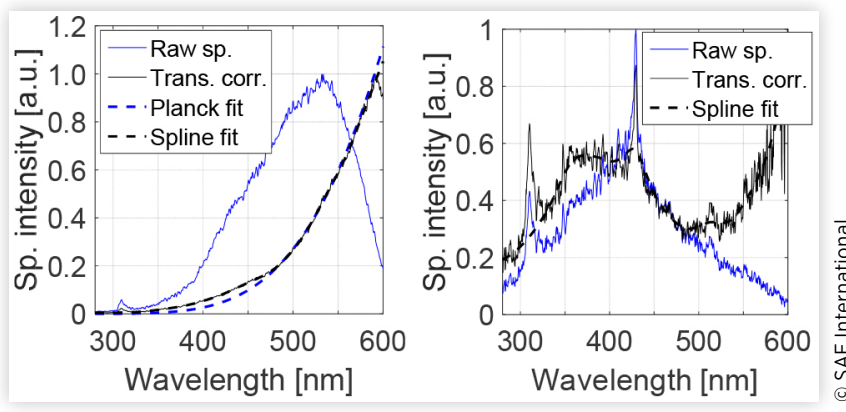

to $585 \mathrm{~nm}$. The soot emissivity relation ${ }^{3}$ proposed by Musculus [37] has been used. In this spectral range the contribution of interference through the flame fluorescence is expected to be smallest in the available spectral range. The result of the fitting procedure is a value of an apparent soot temperature $\left(\mathrm{T}_{\text {s-app }}\right)$ at the spatial location of the spectrum. The dashed curve in Figure 6 demonstrates the resulting Planck's law curve fit resulting in an estimated apparent temperature of soot $\mathrm{T}_{\text {s-app }}=2180 \mathrm{~K}$ with $95 \%$ confidence interval width around $\pm 25 \mathrm{~K}$. However, this approach entails some uncertainties with regard to absolute accuracy since the system has not been calibrated with a light source which emission spectrum is known. The system performance might deviate from the manufacturer data due to the component aging and manufacturing deviations. Nevertheless, the aim of this study was to observe trends of soot temperature when changing from Diesel to dual-fuel operation. This can be accomplished well with the present experimental setup calibration.

The wavelength range used for determining the $\mathrm{T}_{\mathrm{s} \text {-app }}$ is suboptimal and the fit of the soot temperature might be corrupted by the flame luminosity. Indeed, investigations of the non-sooting cases (Figure 6 right) show an intense broadband flame luminosity extending from $280 \mathrm{~nm}$ to $600 \mathrm{~nm}$ and beyond, superimposed by peaks from $\mathrm{OH}^{\star}(310 \mathrm{~nm}), \mathrm{CH}^{*}$ $(430 \mathrm{~nm})$ and $\mathrm{C}_{2}{ }^{*}(510 \mathrm{~nm})$. The broadband fluorescence in the wavelength range $250 \mathrm{~nm}$ to $500 \mathrm{~nm}$ is commonly attributed to $\mathrm{CO}_{2}{ }^{*}$ chemiluminescence $[\underline{38}, \underline{39}, \underline{40}]$. The source of emission at wavelengths above $500 \mathrm{~nm}$ is less explored. Some researchers investigating HCCI combustion attributed this emission to water thermal excitation and rotation-vibrational emission of water molecules $[\underline{38}, \underline{40}, \underline{41}]$.

In order to suppress the corruption through flame chemiluminescence, the temperature fit of spectra with flame luminosity intensity exceeding $20 \%$ of the soot incandescence intensity at $450 \mathrm{~nm}$ were rejected as too uncertain.

Due to the line-of-sight nature of the 1D-spectroscopy approach, the soot-temperature measurements have to be interpreted with caution. Gradients of soot temperature along the line of sight result in under-prediction of the soot KL value [42] due to the $\mathrm{T}^{4}$ dependence of the total black body luminosity. According to the Wien's law, in the short wavelength range this dependency is even stronger $\left(\mathrm{T}^{5-15}\right)$. This strongly biases the multi-color detection of $\mathrm{T}_{\text {s-app }}$ towards hottest soot layers along the line of sight.

\section{Calibration of the Spray Mixing Model}

The 1D-spray model developed by Pastor, Desantes and coworkers $[\underline{31}, \underline{43}, \underline{44}, \underline{45}]$ has been employed to predict the pilot fuel mixture distribution at the time of ignition (DICOM software, version 6.3). Based on the model output, the evolution of total fuel mass in the fuel-rich spray zones were computed and used to facilitate the discussion of the observed trends of soot formation for various concentrations of premixed methane.

${ }^{3} \varepsilon(\lambda) \propto \lambda^{-\alpha}, \alpha=1.22-0.245 \cdot \ln (\lambda[\mu \mathrm{m}])$ 
The input parameters to the model were measured massinjection rate of the injector and thermodynamic quantities evolution in the RCEM. The spray cone angle was used as a tuning parameter and the spray penetration, measured by Schlieren imaging, was used to estimate the performance of the model. The Schlichting profile [46] was used to model the radial fuel distribution. For all measured injection durations good agreement of the spray penetration was achieved by setting the spray cone angle to $17^{\circ}$. The measured cone angle at axial distance of $42 \mathrm{~mm}$ was $13.8^{\circ}$.

Despite the good agreement of modelled and measured spray penetration the required increase of the spray cone angle input in the model is subject to uncertainty regarding validity of the modelled results. The model has been developed for unconstrained spray, which is not the case in the RCEM with the small TDC clearance. This might be the reason for differences between the model and experiment. However, the air entrainment rate is strongly dependent on the cone angle and might be overestimated by the model using the present settings. In the present work the model results have been used only to facilitate the analysis of the experimentally observed trends. We believe the model should still capture these trends reliably.

\section{Results}

\section{Methane Influence on the Pilot Fuel Ignition Delay}

The high-temperature ignition delay of the pilot fuel has been determined based on the $\mathrm{OH}^{*}$ imaging using a thresholding approach. Detection of ignition was defined with an image processing procedure as follows: when the light intensity of $\mathrm{OH}^{*}$ exceeds a threshold of $1 \%$ of the camera dynamic range in area larger than 60 pixel $^{2}$, ignition has occurred. This threshold relates to the lowest intensifier gain and was increased along with the gain for other cases. The sensitivity of ignition delay on the threshold was assessed by varying the threshold from $0.5 \%$ to $2 \%$, which resulted in less than one frame change of the detected ignition delay $(25 \mu \mathrm{s})$.

According to the empirical relation by Idicheria and Pickett [47] $\left(\mathrm{t}_{\mathrm{ign}} \propto\left[\mathrm{O}_{2}\right]^{-1}\right.$, observed under similar conditions) maximal 6\% increase of ignition delay due to the dilution of air through methane can be expected. A significantly stronger effect of methane on the pilot fuel auto-ignition has been observed in the present study (Figure 7), indicating a chemical involvement of methane in the autoignition process.

When adding methane with $\phi_{\mathrm{CH} 4}=0.59$ into the air charge up to $40 \%$ increased ignition delays have been observed. This sensitivity of the ignition delay on methane concentration was higher under less reactive conditions, as recognized by the steeper gradient of the ignition delay curves at lower temperatures (Figure 7). Generally shorter injections showed a tendency to have shorter ignition delays, which can be explained by a faster availability of reactive mixture due to the entrainment wave after the end of injection (EOI) [48].
FIGURE 7 Ignition delay dependence on the methane concentration $\phi$, variation of $\mathrm{T}_{\mathrm{SO}}$ and injection duration (error bars: $\mathrm{ET}=700 \mu \mathrm{s}$, crosses: $\mathrm{ET}=500 \mu \mathrm{s}$, circles: $\mathrm{ET}=400 \mu \mathrm{s}$ ).

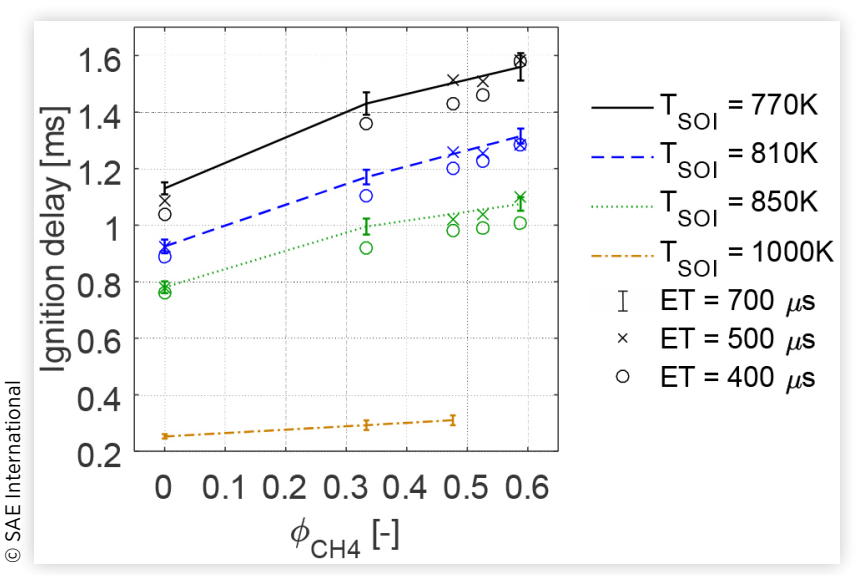

On the other hand, the variation of the injection duration did not considerably influence the sensitivity of the ignition delay to methane concentration.

The effect of methane prolonging the ignition process of the pilot fuel has been previously observed in rapid compression machines $[19, \underline{20}, \underline{21}$, optical engines [49] and dual-fuel engines $[11, \underline{13}, \underline{50}]$. This influence has been attributed to interception of reactive radicals by methane. In the present work the ignition retardation effect of methane is of interest since it prolongs the dwell time between EOI and ignition, thus influencing the soot propensity.

\section{Influence of Methane on Pilot Fuel-Jet Soot Propensity}

The DBI-imaging based ensemble-averaged line-of-sight KL distribution has been used as a measure of combustion sooting propensity. The analysis of the methane influence on sooting behavior of the $n$-dodecane spray has been assessed based on a comparison of cases with approximately same ignition delay (constant pilot fuel mixture fraction at ignition) and comparison of cases with methane variation while maintaining charge temperature. All considered cases are transient with the ignition dwell larger than $-0.4 \mathrm{~ms}$.

In the following, the reference case utilizing $n$-dodecane injection into the air with no methane will be referenced as the "Diesel case", while the term "dual-fuel case" refers to the injections of $n$-dodecane into the methane/air charge.

Figure 8 shows the evolution of average soot optical density for three cases with varying premixed methane equivalence ratio $\left(\Phi_{\mathrm{CH} 4}=0,0.33,0.59\right)$ with approximately the same ignition delay $\left(\mathrm{T}_{\mathrm{SOI}}=770 \mathrm{~K}, 810 \mathrm{~K}\right.$ and $850 \mathrm{~K}$, ignition delay in the range of 1.1-1.2 ms). Additionally, the bottom plot in Figure 8 presents the total detected soot quantity as estimated by summation of the DBI signal across the field of view (FoV). The ignition dwell is close to zero (injector ET $=700 \mu \mathrm{s}$ ). With addition of premixed methane the stoichiometric equivalence ratio of the dodecane jet shifts towards the fuel jet boundary and reduces the temperature and oxygen availability in the spray core. The observed peak amount of soot increases by a 
FIGURE 8 Evolution of soot cloud optical thickness for three cases with similar ignition delay: $770 \mathrm{~K} \Phi_{\mathrm{CH} 4}=0$ (upper row), $810 \mathrm{~K} \Phi_{\mathrm{CH} 4}=0.33$ (middle row), $850 \mathrm{~K} \Phi_{\mathrm{CH} 4}=0.59$ (lower row). Pilot injection: $E T=700 \mu \mathrm{s}, \mathrm{p}_{\mathrm{inj}}=600$ bar. The black dashed contour shows the boundary of the FoV. The bottom plot shows the evolution of the total soot quantity in arbitrary units, estimated by integration of the DBI signal across the FoV. The time instant when part of the soot leaves the FoV is indicated with a black dashed line.

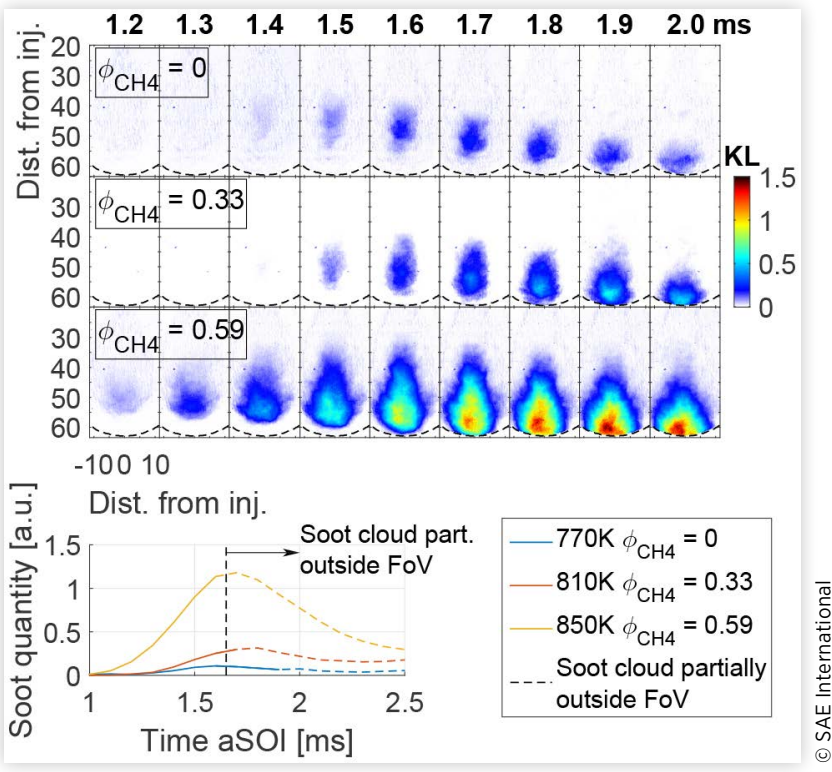

factor of 12 from the Diesel case $(770 \mathrm{~K})$ to a dual-fuel case $\left(850 \mathrm{~K} \Phi_{\mathrm{CH} 4}=0.59\right)$.

The higher soot propensity of dual-fuel combustion and the higher charge temperature result in faster soot inception as shown by earlier appearance of soot (Figure 8). A wider and longer spread of the dual-fuel soot cloud indicates that the presence of methane widens the band of pilot fuel equivalence ratio favorable for soot production. In the Diesel case, the soot formation process finishes soon after the first soot is formed and the remaining soot cloud is transported further downstream where it subsequently oxidizes. In the dual-fuel cases, the soot formation appears also upstream of the location of the first soot formed. In the most sooting case an elongated soot cloud is formed extending to a distance of $35 \mathrm{~mm}$ from the injector (at $1.6 \mathrm{~ms}$ aSOI). The highest soot concentration under this condition is observed at the transient spray head. By the time of $1.7 \mathrm{~ms}$ aSOI the soot cloud reaches the edge of the RCEM window and a part of it leaves the field of view, as indicated with a black dashed line (Figure 8). Therefore, the present setup does not allow a complete observation of soot oxidation at the spray tip. Nevertheless, the peak optical density of the soot does not decrease until $2 \mathrm{~ms}$ after SOI in both cases with the presence of methane. This indicates inhibition of the soot oxidation through methane - the effect persists up to a late cycle stage due to slow mixing long time after EOI.

A comparison of the soot KL-value distributions for a variation of premixed methane equivalence ratio at the charge temperature of $850 \mathrm{~K}$ for the $700 \mu \mathrm{s}$ ET injection is shown in
FIGURE 9 Evolution of soot cloud optical thickness for variation of the premixed methane equivalence ratio at constant $\mathrm{T}_{\mathrm{SOl}}=850 \mathrm{~K}: \Phi_{\mathrm{CH} 4}=0$ (upper row), $\Phi_{\mathrm{CH} 4}=0.33$ (middle row), $\Phi_{\mathrm{CH} 4}=0.59$ (lower row). Pilot injection: $\mathrm{ET}=700 \mu \mathrm{s}, \mathrm{p}_{\mathrm{inj}}=600$ bar. The black dashed contour shows the boundary of the FoV. The bottom plot shows the evolution of the total soot quantity in arbitrary units, estimated by integration of the DBI signal across the FoV. The time instant when part of the soot leaves the FoV is indicated with a black dashed line.

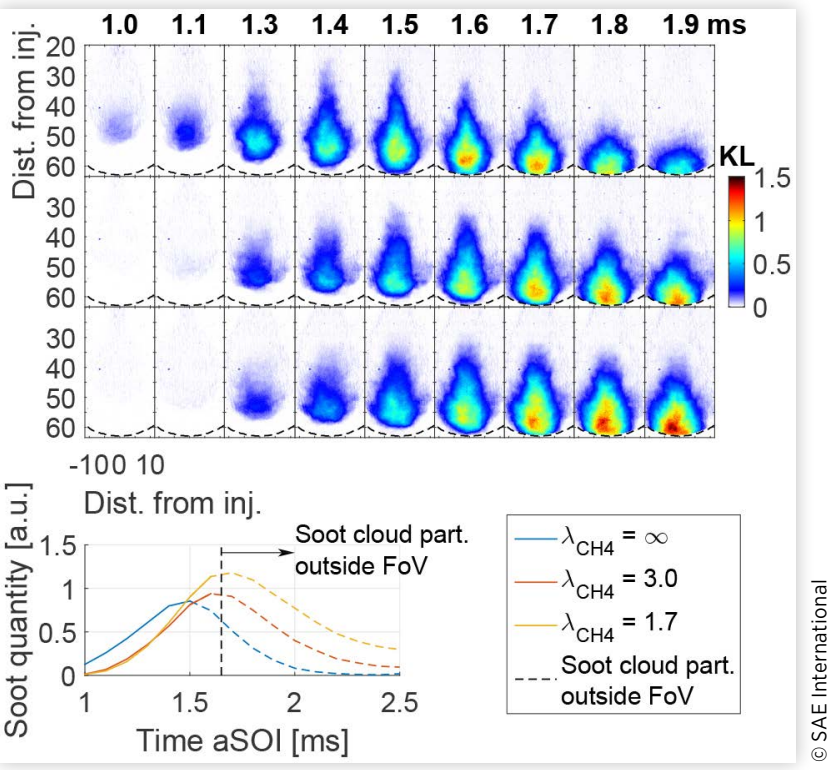

Figure 9. Due to the influence on the pilot fuel ignition delay both the pilot fuel equivalence ratio at the time of ignition and the availability of oxygen in the pilot fuel plume change with this variation. Contrary to the case with constant ignition delay, the formation of soot is deferred by addition of methane due to the increased ignition delay. The highest soot concentrations are detected later in the cycle. For all methane concentrations the initial soot is formed at the spray tip and - as the spray evolves - the soot formation region shifts further upstream. The shortest distance between soot cloud and injector increases with the addition of methane. This effect has been attributed to leaning of the jet wake after the EOI and to later onset of soot formation. In the dual-fuel cases the soot is oxidized at a significantly slower rate than in the Diesel case due to the lower oxygen availability in the burnt premixed zone. While the axial profile of the soot cloud strongly changes with the addition of methane the radial profile and width of the soot distribution close to the spray tip does not change considerably. Hence this indicates that methane mostly influences soot oxidation through lower availability of oxygen.

On the other hand, the initial soot production seems to be mostly influenced by the local equivalence ratio of the Diesel surrogate fuel and less by the availability of oxygen. According to the HACA soot formation mechanism, absence of $\mathrm{C}-\mathrm{C}$ bonds renders methane less prone to soot formation than dodecane. Under certain conditions, alternative chemical pathways of methane forming acetylene as soot precursor are 
possible: for example dehydration of ethylene, formed from methyl radicals originating from the methane thermal decomposition [51]. In dual-fuel combustion methane significantly increases local overall equivalence ratio in the pilot-spray core and therefore inhibits oxidation of both soot and its precursors - thus increasing and prolonging the soot production period of already sooting pilot-fuel combustion in addition to its own sooting propensity. Change of $\mathrm{T}_{\mathrm{ad}}$ and/or change of chemical timescales are further possible effects. An analysis of the reaction pathways using a chemical mechanism which includes dodecane, methane and soot chemistry could shed more light of this complex interplay.

In general, for long injections under hot conditions an increased soot amount and slower oxidation of soot have been observed in the dual-fuel cases compared to the pilot fuel only case. Figure 10 shows the evolution of the soot quantity for a variation of ET and $\phi_{\mathrm{CH} 4}$, thus including also less sooting conditions from the measurement matrix. Note that the soot amount for $400 \mu \mathrm{s}$ and $500 \mu$ s injection ET is multiplied by a factor of 10. For all injection durations the soot formation is delayed in the presence of methane due to the increased ignition delay. Contrary to the trend for a long injection, the $500 \mu \mathrm{s}$ ET injection shows the smallest soot amount for the medium equivalence ratio of methane. Furthermore, the shortest injection shows a detectable soot amount only in the Diesel case while both dual-fuel cases show no soot signal above the noise level of the DBI imaging. This is attributed to the influence of methane on the ignition delay. In case of a short injection, the prolonged ignition delay leads to a further drop of the equivalence ratio of the pilot fuel, eventually falling below the threshold of soot production.

The trend inversion of methane influence on sooting propensity presented in Figure 10 has been invoked by decreasing the injection duration at constant $\mathrm{T}_{\mathrm{SOI}}$. A similar trend inversion has been also observed for the long injection $(\mathrm{ET}=700 \mu \mathrm{s})$ and variation of $\mathrm{T}_{\mathrm{SOI}}$. At $770 \mathrm{~K} \mathrm{~T}_{\mathrm{SOI}}$ sufficiently large ignition dwell has been reached and combustion in the presence of methane did not produce any measurable soot.

FIGURE 10 Temporal evolution of the soot quantity, at $\mathrm{T}_{\text {SOI }}=850 \mathrm{~K}$, for a variation of the background equivalence ratio for three different injection durations: $\mathrm{ET}=400 \mu \mathrm{s}$ (dotted line, quantity multiplied by 10 ), ET = $500 \mu$ s (dashed line, quantity multiplied by 10), ET = $700 \mu$ s (full line). The range of ignition delays for different $\phi_{\mathrm{CH} 4}$ and the EOI time instants are marked with arrows.

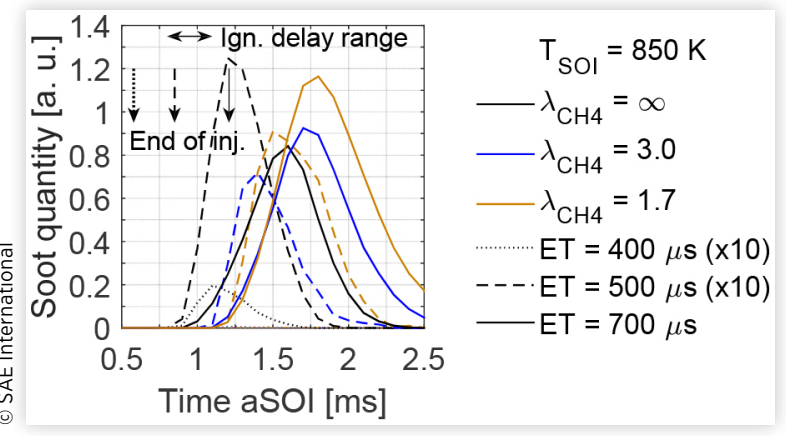

(c) 2018 SAE International. All Rights Reserved.

\section{Discussion}

\section{Soot Formation Dependence on the Ignition Dwell Time}

A strong dependence of the sooting propensity on the injection duration has been observed. All cases considered in this study are transient, with ignition dwell times between EOI and ignition exceeding $-0.4 \mathrm{~ms}$ and reaching up to $+0.8 \mathrm{~ms}$. The entrainment wave after the EOI causes fast mixing and the equivalence ratio in the spray drops rapidly. Figure 11 shows the model-predicted temporal evolution of the fuel mass in the spray exceeding the threshold mixture fraction for soot production.

The evolution of available mass in the fuel-rich zones begins similarly for all injection durations until the EOI. Following the EOI, the fuel-rich regions of $\phi>2$ disappear after approximately $0.3 \mathrm{~ms}$, which implies that no soot is expected in cases with the ignition dwell exceeding $0.3 \mathrm{~ms}$. This is in good agreement with the observed dependence of soot propensity on the premixed methane concentration reported in Figure 10. The long injection $(\mathrm{ET}=700 \mu \mathrm{s}$, approximately $1.2 \mathrm{~ms}$ hydraulic injection duration) has a negative ignition dwell for all methane concentrations and shows a strongly sooting behavior with soot concentration increasing with higher $\phi_{\mathrm{CH} 4}$. The ET $=500 \mu$ s injection has a small positive ignition dwell $(0.05-0.3 \mathrm{~ms})$, and moderate influence of methane on the sooting propensity can be observed experimentally. The decrease of the pilot fuel equivalence ratio due to the increased ignition delay is compensated by the methane itself. In case of a short injection $(\mathrm{ET}=400 \mu \mathrm{s})$, the ignition dwell exceeds $0.2 \mathrm{~ms}$ which correlates well to the time limit of existence of the pilot-fuel-rich regions. Therefore, the addition of methane decreases soot formation.

FIGURE 11 1D spray model predicted quantity of the fuel exceeding the threshold equivalence ratio for a variation of injection duration (full line: $\phi=1.5$, dashed line: $\phi=2$, dash-dotted line: $\phi=2.5$ ). The time instants of the EOI are marked with vertical arrows.

Horizontal arrows show the experimentally

determined ignition delay range $\left(\phi_{\mathrm{CH} 4}\right.$ variation) for different $\mathrm{T}_{\mathrm{SO}}$.

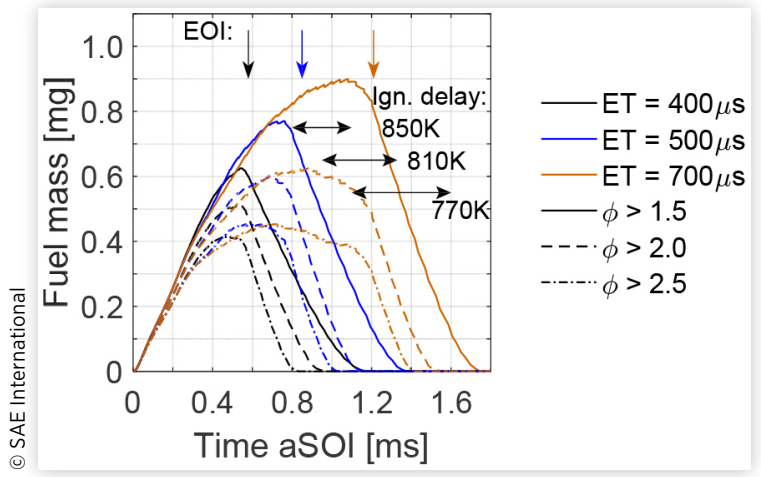




\section{Correlation of Soot Temperature and Oxidation}

In the $\phi$-T space of Diesel diffusion flames the existence of soot is usually limited to the temperature range between $1600 \mathrm{~K}-2600 \mathrm{~K}$ and fuel equivalence ratio in excess of around 2 , somewhat dependent on the sooting propensity of the employed fuels. However, the realizable conditions in the $\phi-T$ space of diffusion flames are restricted by the adiabatic flame temperature, flammability limits of the fuel and scalar dissipation rate. General wisdom of the soot formation process suggests that soot is formed in the fuel-rich cold mixtures and is subsequently oxidized where the equivalence ratio drops towards a value of 2 and temperature increases. In the fuel-rich burnt mixture the temperature is monotonously increasing with decreasing $\phi$. This consideration can distinguish soot formation and oxidation regions based on the soot radiation apparent temperature.

In the presence of temperature gradients along the line of sight this analysis is afflicted with the bias of the apparent temperature towards the hottest soot [42]. Furthermore, the soot optical properties might change during oxidation and/ or in the presence of methane. Both effects have to be considered when drawing conclusions based on the apparent soot temperature $\left(\mathrm{T}_{\mathrm{s} \text {-app }}\right)$.

To establish the framework of the analysis, a high temperature case with a short injection $(\mathrm{ET}=300 \mu \mathrm{s})$ has been selected. Due to the high $\mathrm{T}_{\text {SOI }}$ the cases are strongly sooting. However, the entire soot is also oxidized within the visible field of the RCEM window. Figure 12 presents the evolution of the soot optical density dependence on methane, for the selected short injection high-temperature case. Soot is formed immediately after ignition. Similarly as in the cases at lower temperature, introduction of methane moderately increases the peak soot concentration and delays the soot oxidation. In case without methane the soot is completely oxidized after $1.5 \mathrm{~ms}$ aSOI while in the case of $\phi_{\mathrm{CH} 4}=0.48$ soot persists up to $2 \mathrm{~ms}$ aSOI.

The temporal evolution of the $1 \mathrm{D}$-resolved $\mathrm{T}_{\mathrm{s} \text {-app }}$ along the injector axis for the high-temperature case is shown in Figure 13. The abscissa resolves the time aSOI and the ordinate resolves the distance from the injector orifice. The apparent temperature of the first soot formed is about $2050 \mathrm{~K}$ and quickly drops to $1950 \mathrm{~K}$. The coldest temperature is observed approximately $0.2 \mathrm{~ms}$ before the maximal soot concentration. The temperature in the optically most dense region of the soot cloud then rises up to around $2200 \mathrm{~K}$ and peaks at roughly $2400 \mathrm{~K}$ before the DBI soot signal decreases below its detection limit. The $\mathrm{T}_{\text {s-app }}$ in the wake of the soot cloud reaches $2400 \mathrm{~K}$ at approximately the same time as the soot reaches its peak amount. A band of soot with high apparent temperature persists in the wake of the soot cloud until the soot is oxidized. Similar behavior has been observed for the dual-fuel combustion cases as well.

In order to further facilitate the analysis, the detected soot temperature has been compared to the adiabatic flame temperature in the $\phi$-T space (see Figure 14). The $\mathrm{T}_{\text {ad }}$ has been calculated by equilibrium calculations under constant pressure conditions, using the detailed chemistry mechanism
FIGURE 12 Evolution of soot cloud optical thickness for variation of the premixed methane equivalence ratio $\left(\mathrm{T}_{\mathrm{SOl}}=1000 \mathrm{~K}\right.$ ): $\Phi_{\mathrm{CH} 4}=0$ (upper row), $\Phi_{\mathrm{CH} 4}=0.33$ (middle row), $\Phi_{\mathrm{CH} 4}=0.47$ (lower row). Pilot injection: $\mathrm{ET}=300 \mu \mathrm{s}$, $\mathrm{p}_{\mathrm{inj}}=1000$ bar. The bottom diagram shows the evolution of the total soot quantity in arbitrary units, estimated by integration of the DBI signal across the visible field.

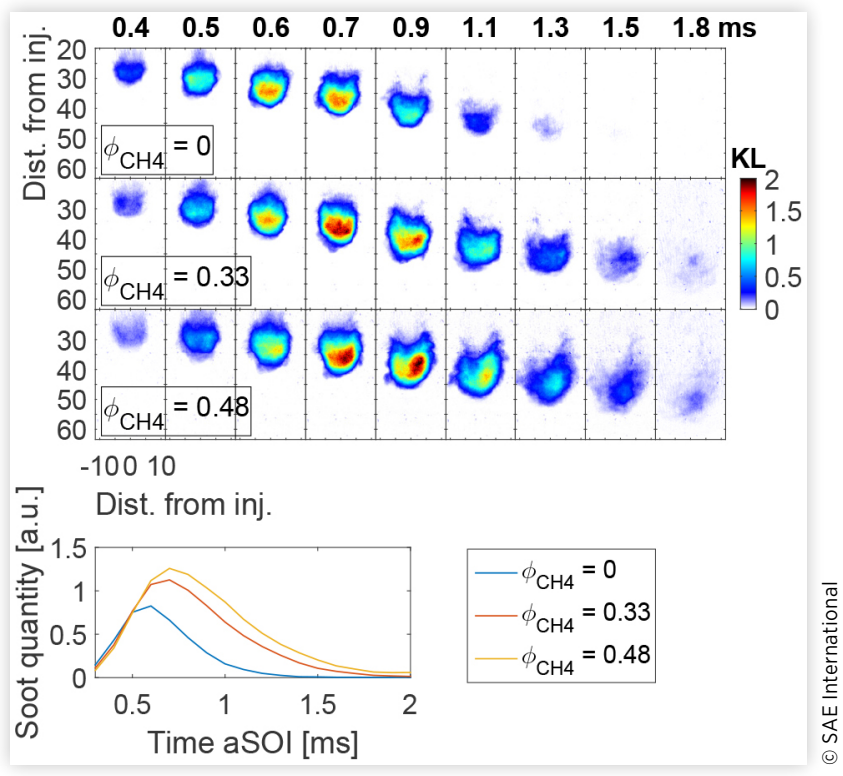

FIGURE 13 Temporal evolution of the 1D resolved line-ofsight $\mathrm{T}_{\mathrm{s} \text {-app }}$ along the injector axis for a variation of premixed methane equivalence ratio. Conditions: $\mathrm{T}_{\mathrm{SO}}=1000 \mathrm{~K}$,

$\mathrm{ET}=300 \mu \mathrm{s}, \mathrm{p}_{\text {inj }}=1000$ bar.

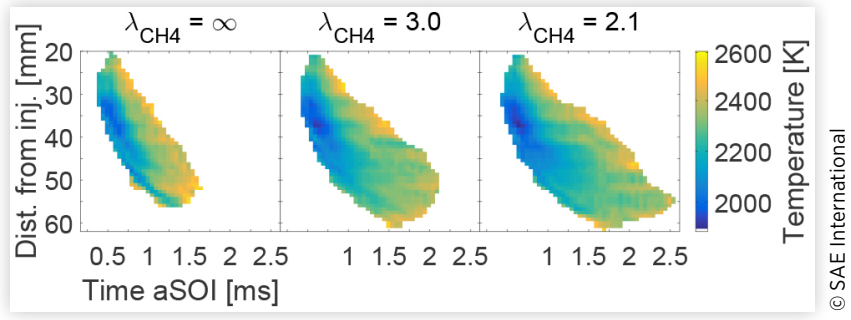

from Sarathy et al. [52]. Mixture cooling due to the adiabatic mixing and fuel evaporation has been considered. At $1000 \mathrm{~K}$ charge temperature the adiabatic flame temperature peaks at $2770 \mathrm{~K}$ in a slightly rich mixture. In methane/air mixtures the peak $\mathrm{T}_{\mathrm{ad}}$ changes negligibly $\left(30 \mathrm{~K}\right.$ at $\left.\phi_{\mathrm{CH} 4}=0.6\right)$ while $\phi_{\mathrm{n}-\mathrm{C} 12}$ at the peak $\mathrm{T}_{\mathrm{ad}}$ shifts to leaner conditions. In the case with pilot fuel only, the formation of soot is expected to be in the range between $1700 \mathrm{~K}$ and $2100 \mathrm{~K}$ at an equivalence ratio exceeding 2 . Indeed, the detected apparent temperature range during the initial stage of the soot formation is in agreement with this expectation, especially if the bias towards hotter soot along the line of sight is taken into account (this influence is assessed below). In methane/air mixtures the $\mathrm{T}_{\mathrm{ad}}$ in the soot forming region decreases by roughly $400 \mathrm{~K}\left(\phi_{\mathrm{CH} 4}=0.6\right)$ at same $\phi_{\mathrm{n}-\mathrm{C} 12}$. The experiments also showed a trend of decreasing soot temperature with increasing $\phi_{\mathrm{CH} 4}$ (Figure 13) - but only 
with $1 / 3$ of the sensitivity predicted by the drop of $\mathrm{T}_{\mathrm{ad}}$. This suggests that soot formation conditions in dual-fuel combustion cases do shift towards leaner pilot fuel mixture fractions, as will be further discussed in the next section.

The $\mathrm{T}_{\text {s-app }}$ detected by the line-of-sight methods is inflected by the hottest layers of soot and therefore showing a high-temperature bias in respect to the mass-averaged soot temperature. A temperature bias of up to $300 \mathrm{~K}$ has been predicted by Musculus et al. [42], calculated based on 3D simulations. In this study, the degree of this bias has been evaluated by utilizing a simple two-layer soot model as previously used by Kamimoto et al. [53]. Figure 15 (left) presents a schematic of the model: it assumes that the soot cloud consists of a cold fuel-rich inner-core and a thinner hot layer at the boundaries, where the soot is being oxidized. Along the lineof-sight the black body luminosity of three layers contributes to the soot signal: luminosity of soot oxidation layer 1 (L1), luminosity of layer 2 (L2) reduced by absorption within L1; and L2 reduced by the absorption within L1 + L2. Based on the optical thickness and temperature of the L1 and L2 the mass-averaged temperature as well as the $\mathrm{T}_{\mathrm{s} \text {-app }}$ in the wavelength range of interest has been calculated.

In the model, the range of soot temperatures for both layers is derived from the $T_{a d}$ for the range of $\phi$ expected in each layer: $\phi$ in the range between 1.2 and 2 has been assumed for oxidation layer L1 and $\phi$ between 2 to 3 for the soot-cloud core L2. This corresponds to the temperature range 2150$2720 \mathrm{~K}$ in L1 and 1570-2150 K in L2. Figure 15 (right) shows the calculated temperature bias ( $\mathrm{T}_{\text {bias }}$ ) between the $\mathrm{T}_{\text {s-app }}$ and mass-averaged soot temperature for two different soot cloud optical thicknesses: view 1 (more upstream) assumes a thin soot cloud $\left(\mathrm{KL}_{\mathrm{L} 2}=0.3\right)$ and view 2 a thick soot cloud $\left(\mathrm{KL}_{\mathrm{L} 2}=2\right)$. The optical thickness of the soot oxidation layer was presumed thin and kept constant $\left(\mathrm{KL}_{\mathrm{L} 1}=0.1\right)$. At the highest difference in soot temperature between the layers the model-predicted a temperature bias up to $1000 \mathrm{~K}$. At a more realistic temperature gradient of $500 \mathrm{~K}$ the temperature bias reached up to $300 \mathrm{~K}$, which is in line with the results in [42]. Furthermore, it can be observed that the temperature bias does not exceed $100 \mathrm{~K}$ if the temperature gradient is below $250 \mathrm{~K}$ in the thin cloud (view 1) or $350 \mathrm{~K}$ in the optically thick soot cloud (view 2).

Based on the information regarding the $\mathrm{T}_{\mathrm{ad}}$ (Figure 14) and considering the two-layer model results (Figure 15), the observed temperature distribution (Figures 13 and $\underline{16}$ in next section) has been interpreted as follows: $\mathrm{T}_{\text {s-app }}$ exceeding $2400 \mathrm{~K}$ indicates presence of a hot soot layer along the line of sight. Due to the high temperature, which suggests relatively lean conditions $(\phi<1.6)$, it is safe to assume that in such layers strong soot oxidation is taking place. On the other side of the temperature scale, the formation of soot is expected to take place in regions with $\phi>2$, which corresponds to $T_{a d}<2150 \mathrm{~K}$. Therefore, $\mathrm{T}_{\mathrm{s} \text {-app }}$ below $2150 \mathrm{~K}$ indicates presence of a cold soot region along the line-of-sight, where conditions for soot formation are fulfilled. This condition applies even if large gradients along the line of sight are present. Furthermore, this indicates an optically very thin or rather cold oxidation zone, which does not exhibit the radiative power to bias the $\mathrm{T}_{\text {s-app}}$. The intermediate temperature range cannot be interpreted in a straightforward manner since a large range of
FIGURE 14 Adiabatic flame temperature dependence on pilot fuel equivalence ratio $\left(\phi_{\mathrm{n}-\mathrm{Cl} 2}\right)$ and $\phi_{\mathrm{CH} 4}$ for $\mathrm{T}_{\mathrm{SOl}}=1000 \mathrm{~K}$ conditions. The soot formation range for Diesel fuel (reproduced from [37]) is marked in gray.

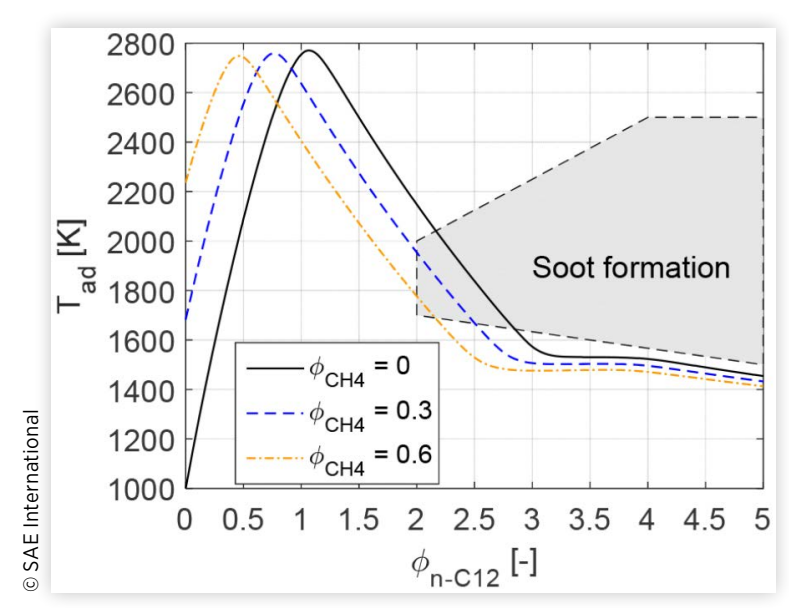

FIGURE 15 Left: Schematic of the two-layer soot cloud model for the estimation of the apparent temperature bias. Right: Model-based approximation of the apparent temperature bias relative to the mass averaged soot temperature. Upper plot: bias for a thin soot cloud (layer L1: $\mathrm{KL}=0.1$, layer $\mathrm{L} 2 \mathrm{KL}=0.3$ ). Lower plot: bias for a thick soot core (layer $\mathrm{L} 1: \mathrm{KL}=0.1$, layer $\mathrm{L} 2: \mathrm{KL}=2$ ).

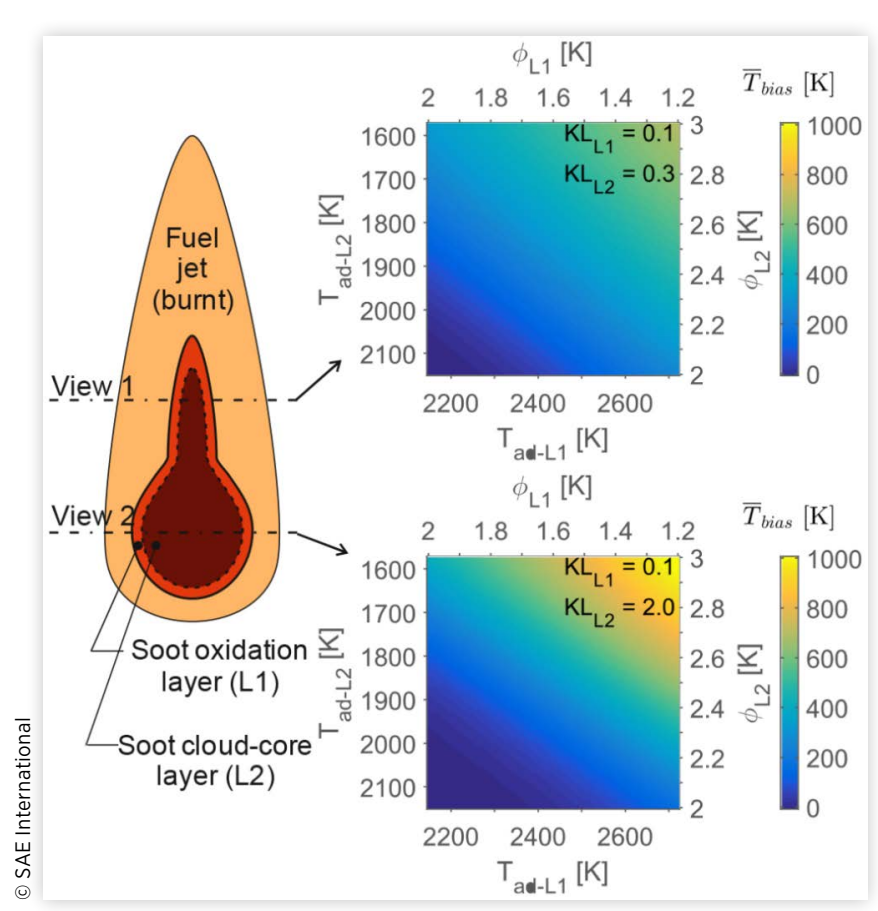

zone-temperature combinations lead to the same $\mathrm{T}_{\mathrm{s} \text {-app }}$. Results have to be evaluated using additional information from measurements of the overall soot optical thickness and by means of understanding the spray mixing process (see Figure 11). In this study, it was assumed that after EOI the soot cloud temperature gradients decrease as the maximal $\phi$ decreases. Therefore, it was speculated that after EOI a higher 
$\mathrm{T}_{\text {s-app }}$ indicates thicker or hotter oxidation layer resulting in higher soot oxidation rate.

No further conclusions can be made without more detailed information on the soot cloud morphology. The analysis was based on the assumption of constant optical properties of soot as no information on the soot morphology was available.

\section{Methane Influence on Oxidation and Soot Temperature}

The evolution of the $\mathrm{T}_{\text {s-app }}$ for variation of the $\phi_{\mathrm{CH} 4}$ at constant ignition delay is presented in Figure 16a. The temperature range is between $2000 \mathrm{~K}$ and $2600 \mathrm{~K}$. The regions with the highest soot density appear to have the lowest apparent temperature. Strong soot oxidation ( $\mathrm{T}_{\text {app }}>2400 \mathrm{~K}$ ) has only been detected in the wake of the jet. As the soot cloud is transported away by the jet convection it leans out and the $\mathrm{T}_{\mathrm{s} \text {-app }}$ slowly increases, indicating stronger oxidation. In the case without methane, the entire soot cloud is oxidized approximately at the same time as the cloud reaches the edge of the window and the apparent temperature reaches close to $2300 \mathrm{~K}$. Comparison of the three cases with same ignition delay indicates a colder soot-dense cloud in the dual-fuel cases despite the increased $\mathrm{T}_{\mathrm{SOI}}$. This indicates soot formation at higher $\phi$ and in absence of a hot oxidation layer along the line-of-sight. The slower rise of the dense cloud apparent temperature indicates colder or thinner soot oxidation layer and therefore, slower oxidation of the core soot cloud. The oxidation of soot in the jet wake appears to take place in the similar temperature range.

The $\mathrm{T}_{\text {s-app }}$ evolution for the variation of the premixed methane equivalence ratio at constant $\mathrm{T}_{\mathrm{SOI}}=850 \mathrm{~K}$ is presented in Figure 16b. A significantly lower temperature of

FIGURE 16 Temporal evolution of the 1D resolved line-ofsight $\mathrm{T}_{\mathrm{s} \text { app }}$ along the injector axis for a variation of premixed methane equivalence ratio. Pilot injection: $\mathrm{ET}=700 \mu \mathrm{s}$,

$p_{\text {inj }}=600$ bar.

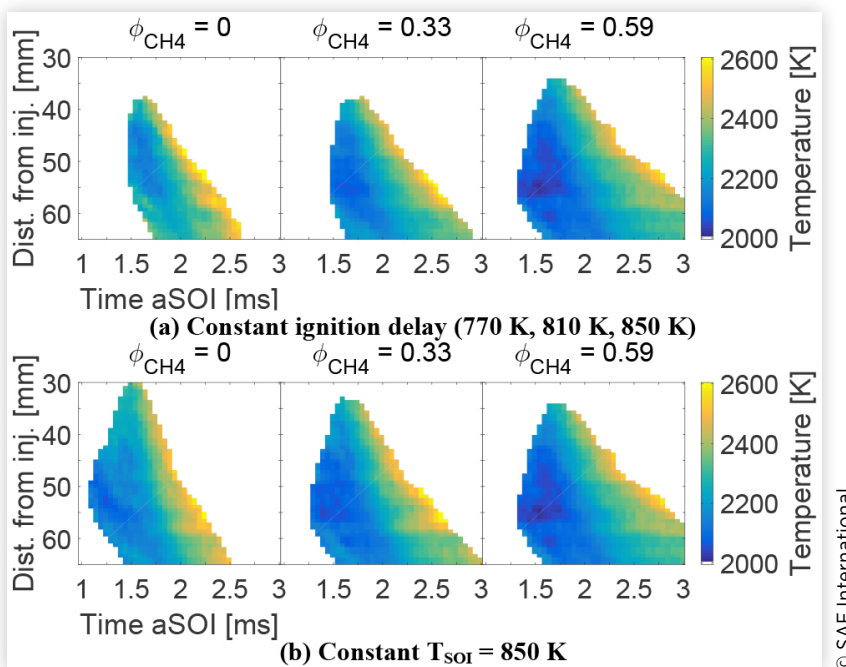

the dense soot cloud has been measured in the dual-fuel case. This implies an overall increased equivalence ratio in the soot cloud and thus, lower temperature in the outer soot cloud layer. At the wake of the fuel jet a considerably later rise of the apparent temperature and therefore, delayed oxidation of soot was observed when methane has been added to the air charge. In the Diesel case the soot cloud completely left the observable domain by the time of $2.7 \mathrm{~ms}$ aSOI while longer persistence of soot is observed in dual-fuel cases. Generally, in dual-fuel combustion cases lower temperatures in the entire domain have been observed. This is in agreement with the observation that soot in dual-fuel cases oxidizes at a slower rate.

The mean soot temperature evolution for a range of conditions is plotted in Figure 17, calculated by weighted averaging of temperature along the axis with the black-body luminosity based soot quantity weights used. In a transient environment like in the RCEM two effects can influence the mean soot temperature: change of the burnt zone $\mathrm{T}_{\mathrm{ad}}$ by air entrainment and through compression/expansion of the burnt gases due to the piston motion. To be able to distinguish between the contribution of each of the effects, additionally the evolution of the burnt mixture temperature at $\phi=2$ is plotted in Figure 17.

The mean soot temperature shows a similar evolution for all considered conditions. After the initial soot is formed in the temperature range of $2080 \mathrm{~K}$ to $2200 \mathrm{~K}$, the mean soot temperature increases monotonously exceeding $2400 \mathrm{~K}$ before the soot is fully oxidized and the signal disappears. The increase of the temperature is considerably higher than what could be expected because of the compression of burnt gases, which indicates that a leaning of the air charge is responsible for the increasing soot temperature. Under some conditions, very high soot temperatures have been detected in the final stage before soot oxidation. It is questionable whether soot should be oxidized before such high temperatures are reached, although the detected temperatures do not exceed the stoichiometric $\mathrm{T}_{\mathrm{ad}}$. Possible influences include interference from flame luminosity and change of soot morphology yielding different optical properties of the soot $[29,54]$.

A moderate change of the soot cloud optical density does not considerably change the $\mathrm{T}_{\mathrm{s} \text {-app }}$. Therefore, dependence of the $\mathrm{T}_{\text {s-app }}$ on $\phi_{\mathrm{CH} 4}$ can give an indication of the fuel equivalence

FIGURE 17 Dependence of average $\mathrm{T}_{\mathrm{s} \text {-app }}$ on $\mathrm{T}_{\mathrm{SO}}, \phi_{\mathrm{CH} 4}$ and injection duration (ET).

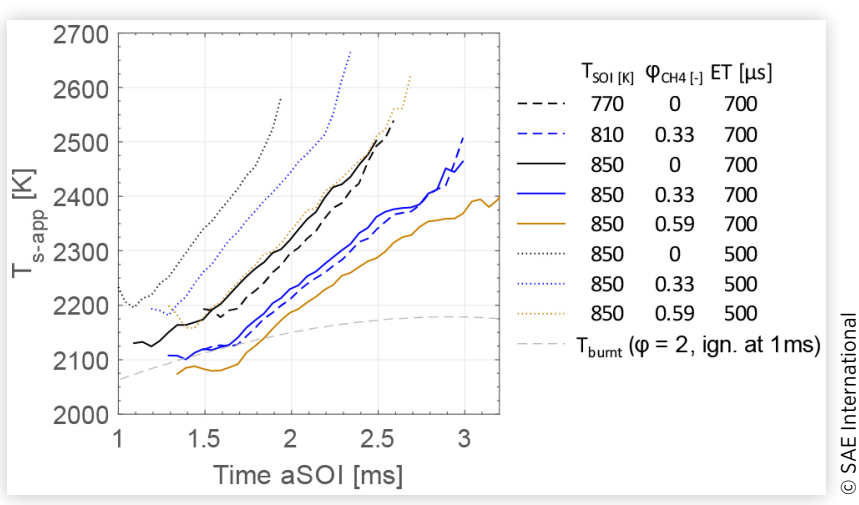

(c) 2018 SAE International. All Rights Reserved. 
ratio of the soot cloud. Even when strong gradients along the line-of-sight are present, the change of $\mathrm{T}_{\mathrm{s} \text {-app }}$ alludes a $\phi$ change in the hottest soot layer. A $200 \mathrm{~K}$ reduction of the soot temperature for $\phi_{\mathrm{CH} 4}=0.6$ relative to the pilot-fuel-only case has been observed for all conditions. This temperature offset did not change considerably up to $2 \mathrm{~ms}$ aSOI and became larger at later stages, just before soot oxidation. Regarding the influence of methane on the $\mathrm{T}_{\mathrm{ad}}$, the detected temperature drop corresponds to approximately $50 \%$ of the $\mathrm{T}_{\mathrm{ad}}$ decrease due to methane at constant $\phi_{\mathrm{n}-\mathrm{C} 12}$. This suggests that $\phi_{\mathrm{n}-\mathrm{C} 12}$ influences the soot formation to a greater extent than the overall equivalence ratio. However, the assumption that $\phi_{\mathrm{CH} 4}$ only influences soot oxidation and does not influence the formation of soot seems to be incorrect. Otherwise, the reduction of $\mathrm{T}_{\text {s-app }}$ would fully correspond to the reduction of the $\mathrm{T}_{\mathrm{ad}}$ with introduction of methane.

Comparing the soot temperature of the low-sooting shorter injection $(\mathrm{ET}=500 \mu \mathrm{s})$ to the longer injection case, a 100-200 K higher soot temperature has been observed. This can be explained by leaner fuel mixture in the spray core at the time of ignition and earlier start of soot oxidation. In longer injection cases, the $\mathrm{T}_{\text {s-app }}$ can be attributed to larger contribution of dense soot located in colder, more fuel-rich regions along the line of sight.

The sooting long injection cases $(\mathrm{ET}=700 \mu \mathrm{s})$ acquired at lower $\mathrm{T}_{\mathrm{SOI}}$ have also been included in the analysis. The decreased temperature results in a reduced $\mathrm{T}_{\mathrm{ad}}$ which transfers to the lower $\mathrm{T}_{\text {s-app }}$. This decrease of the soot temperature $(30 \mathrm{~K}$ at $\left.\mathrm{T}_{\mathrm{SOI}}=770 \mathrm{~K}\right)$ is, however, less than the expected value of around $80 \mathrm{~K}$ based on the decreased $\mathrm{T}_{\mathrm{SOI}}$. A similar explanation as for short injections can be offered here as well: decreasing the $\mathrm{T}_{\mathrm{SOI}}$ resulted in leaner conditions at ignition and therefore faster onset of soot oxidation in the hot outer regions of the soot cloud. These regions dominate the $\mathrm{T}_{\text {s-app }}$ and this effect partially compensates the drop of the $\mathrm{T}_{\mathrm{SOI}}$.

\section{Summary/Conclusions}

The sooting propensity of pilot ignited lean-premixed methane dual-fuel combustion has been experimentally investigated in a rapid compression-expansion machine. A single-hole Diesel injector has been used to admit dodecane pilot fuel into a premixed compressed mixture of methane and air. $\mathrm{OH}^{*}$ chemiluminescence and Schlieren imaging has been employed to acquire the soot-formation relevant metrics like pilot spray penetration and ignition delay. The sooting propensity of the combustion has been investigated by means of high-speed diffuse back-illumination imaging to acquire 2D information on soot optical density. Furthermore, high-speed 1D resolved spectral acquisitions of the soot luminosity has been performed in parallel to determine the apparent temperature of soot along the injector axis.

Based on the analysis of the experimental results, following conclusions can be stated:

1. The ignition delay of the pilot fuel spray is prolonged with increasing concentration of methane in the methane/air charge. This sensitivity on methane increases under less reactive conditions.
2. The sooting propensity of pilot injection under moderately and strongly sooting conditions increases when methane is introduced into the air charge. This is attributed to the addition of carbon through methane and to the decreased availability of oxygen, which lowers the rate of oxidation of soot and its precursors.

3. The influence of methane on the sooting propensity in mildly sooting cases is ambiguous. At ignition, the equivalence ratio of pilot fuel decreases due to the prolonged ignition delay which compensates the larger availability of carbon and decreased oxygen availability. The soot propensity of the combustion remains approximately constant. In very mildly sooting cases the introduction of methane into the air-charge results in non-sooting combustion.

4. By employing $1 \mathrm{D}$-spray simulations it is shown that the ignition dwell time determines the influence of methane on the sooting propensity. Negative ignition dwell cases show increasing soot propensity with methane addition while a reverse trend is observed for the positive ignition dwell cases.

5. The apparent soot temperature detected with $1 \mathrm{D}$ spectroscopy is between $1950 \mathrm{~K}$ and $2600 \mathrm{~K}$. On the lower end of this temperature range, this corresponds to the adiabatic flame temperature at a $\phi \approx 2.5$. On the higher end the temperature approaches the stoichiometric adiabatic flame temperature $(2800 \mathrm{~K})$.

6. In the regions with peak soot formation rate an apparent soot temperature of about $1950 \mathrm{~K}$ to $2150 \mathrm{~K}$ is detected. On the other hand, it is speculated that a hot soot oxidation layer $(\phi<2)$ is present along the line-of-sight in regions with apparent temperatures exceeding $2150 \mathrm{~K}$. Higher temperature indicates a faster oxidation. Regions with highest apparent temperature, and fastest rate of oxidation are found in the wake of the soot cloud during the so-called entrainment wave late in the cycle. Introduction of methane in the air charge results in moderate increase of soot quantity but in considerably slower soot oxidation.

7. In dual-fuel combustion cases (e.g. $\phi_{\mathrm{CH} 4}=0.6$ ) a $200 \mathrm{~K}$ decrease of the mean soot temperature throughout the cycle and up to $20 \%$ increase of the peak optical thickness, compared to the pilot-fuel-only case under same conditions, is observed. This temperature shift is interpreted as an indication that the soot formation and oxidation regions shift to higher overall equivalence ratios due to the lower soot tendency of methane.

8. Shorter injections show higher mean apparent soot temperatures than those for longer injection cases. No dense and cold soot regions are formed. This is attributed to faster onset of soot oxidation due to the lean-out of the pilot fuel jet.

In the present study, the influence of methane on the sooting propensity of pilot-fuel has been compared at constant pilot injection. Contrary, in engine applications the operation is usually based on the principle of substituting the Diesel fuel with methane, keeping the total energy input constant. This 
is achieved by decreasing the injection duration while increasing the $\phi_{\mathrm{CH} 4}$. The observed trend of higher sooting propensity at negative ignition dwell times in the presence of methane and the trend inversion at positive dwell times are expected to apply as well. Transferring this observation to an engine case, with $100 \%$ Diesel operation at start and beginning to substitute the liquid fuel with methane, initially the sooting propensity of combustion might decrease less than expected purely from the decrease of injection duration. Even increased engine exhaust soot emissions cannot be ruled out due to the inhibited oxidation of soot. However, when substitution rate is sufficiently high so that a positive injection dwell is reached, further substitution of liquid fuel will lead to a sharp drop of sooting propensity. An optimal and possibly smokeless operation is expected to be achieved at this point, while further increase of the substitution rate may result in misfire.

Suggestions for further work include a numerical study with a detailed mechanism of the soot precursor formation to better understand the contribution of both fuels towards formation of the soot precursors and soot. In the present study no information on the dual-fuel soot optical properties and morphology was available. The analysis of the sooting propensity and the estimation of the apparent soot temperature would greatly benefit from such additional information.

\section{References}

1. Khan, M.I., Yasmeen, T., Khan, M.I., Farooq, M. et al., "Research Progress in the Development of Natural Gas as Fuel for Road Vehicles: A Bibliographic Review (1991-2016)," Renewable and Sustainable Energy Reviews 66:702-741, 2016, doi:10.1016/j.rser.2016.08.041.

2. Shah, A., Thipse, S.S., Tyagi, A., Rairikar, S.D. et al., "Literature Review and Simulation of Dual Fuel Diesel-CNG Engines," SAE Technical Paper 2011-26-0001, 2011, doi:10.4271/2011-26-0001.

3. Wei, L. and Geng, P., "A Review on Natural Gas/Diesel Dual Fuel Combustion, Emissions and Performance," Fuel Processing Technology 142(Supplement C):264-278, 2016, doi:10.1016/j.fuproc.2015.09.018.

4. Rochussen, J., Yeo, J., and Kirchen, P., "Effect of Fueling Control Parameters on Combustion and Emissions Characteristics of Diesel-Ignited Methane Dual-Fuel Combustion," SAE Technical Paper 2016-01-0792, 2016, doi:10.4271/2016-01-0792.

5. Yang, B., Xi, C., Wei, X., Zeng, K. et al., "Parametric Investigation of Natural Gas Port Injection and Diesel Pilot Injection on the Combustion and Emissions of a Turbocharged Common Rail Dual-Fuel Engine at Low Load," Applied Energy 143(Supplement C):130-137, 2015, doi:10.1016/j.apenergy.2015.01.037.

6. Liu, J., Yang, F., Wang, H., Ouyang, M. et al., "Effects of Pilot Fuel Quantity on the Emissions Characteristics of a CNG/ Diesel Dual Fuel Engine with Optimized Pilot Injection Timing," Applied Energy 110(Supplement C):201-206, 2013, doi:10.1016/j.apenergy.2013.03.024.

7. Egúsquiza, J.C., Braga, S.L., and Braga, C.V.M., "Performance and Gaseous Emissions Characteristics of a
Natural Gas/Diesel Dual Fuel Turbocharged and Aftercooled Engine," Journal of the Brazilian Society of Mechanical Sciences and Engineering 31:142-150, 2009, doi:10.1590/ $\underline{\text { S1678-58782009000200007. }}$.

8. Abdelaal, M.M. and Hegab, A.H., "Combustion and Emission Characteristics of a Natural Gas-Fueled Diesel Engine with EGR," Energy Conversion and Management 64(Supplement C):301-312, 2012, doi:10.1016/j. enconman.2012.05.021.

9. Sun, L., Liu, Y., Zeng, K., Yang, R. et al., “Combustion Performance and Stability of a Dual-Fuel Diesel-Natural-Gas Engine," Proceedings of the Institution of Mechanical Engineers, Part D: Journal of Automobile Engineering 229(2):235-246, 2014, doi:10.1177/0954407014537814.

10. Zhou, L., Liu, Y.-F., Wu, C.-B., Sun, L. et al., "Effect of the Diesel Injection Timing and the Pilot Quantity on the Combustion Characteristics and the Fine-Particle Emissions in a Micro-Diesel Pilot-Ignited Natural-Gas Engine," Proceedings of the Institution of Mechanical Engineers, Part D: Journal of Automobile Engineering 227(8):1142-1152, 2013, doi:10.1177/0954407013480452.

11. Papagiannakis, R.G. and Hountalas, D.T., "Experimental Investigation Concerning the Effect of Natural Gas Percentage on Performance and Emissions of a DI Dual Fuel Diesel Engine," Applied Thermal Engineering 23(3):353-365, 2003, doi:10.1016/S1359-4311(02)00187-4.

12. Papagiannakis, R.G. and Hountalas, D.T., "Combustion and Exhaust Emission Characteristics of a Dual Fuel Compression Ignition Engine Operated with Pilot Diesel Fuel and Natural Gas," Energy Conversion and Management 45(18):2971-2987, 2004, doi:10.1016/j.enconman.2004.01.013.

13. Lounici, M.S., Loubar, K., Tarabet, L., Balistrou, M. et al., "Towards Improvement of Natural Gas-Diesel Dual Fuel Mode: An Experimental Investigation on Performance and Exhaust Emissions," Energy 64(Supplement C):200-211, 2014, doi:10.1016/j.energy.2013.10.091.

14. Abd Alla, G.H., Soliman, H.A., Badr, O.A., and Abd Rabbo, M.F., "Effect of Pilot Fuel Quantity on the Performance of a Dual Fuel Engine," Energy Conversion and Management 41(6):559-572, 2000, doi:10.1016/S0196-8904(99)00124-7.

15. Nithyanandan, K., Gao, Y., Wu, H., Lee, C.-F. et al., "An Optical Investigation of Multiple Diesel Injections in CNG/ Diesel Dual-Fuel Combustion in a Light Duty Optical Diesel Engine," SAE Technical Paper 2017-01-0755, 2017, doi:10.4271/2017-01-0755.

16. Pettinen, R., Kaario, O., and Larmi, M., "Dual-Fuel Combustion Characterization on Lean Conditions and High Loads," SAE Technical Paper 2017-01-0759, 2017, doi:10.4271/2017-01-0759.

17. Dronniou, N., Kashdan, J., Lecointe, B., Sauve, K. et al., "Optical Investigation of Dual-Fuel CNG/Diesel Combustion Strategies to Reduce $\mathrm{CO}_{2}$ Emissions," SAE Int. J. Engines 7:873-887, 2014, doi:10.4271/2014-01-1313.

18. Zhang, Y., Ghandhi, J., and Rothamer, D., "Effects of Fuel Chemistry and Spray Properties on Particulate Size Distributions from Dual-Fuel Combustion Strategies," SAE Int. J. Engines 10(4):1847-1858, 2017, doi:10.4271/2017-01$\underline{1005}$.

19. Schlatter, S., Schneider, B., Wright, Y.M., and Boulouchos, K., "N-Heptane Micro Pilot Assisted Methane Combustion 
in a Rapid Compression Expansion Machine," Fuel 179:339352, 2016, doi:10.1016/j.fuel.2016.03.006.

20. Schlatter, S., Schneider, B., Wright, Y., and Boulouchos, K., "Experimental Study of Ignition and Combustion Characteristics of a Diesel Pilot Spray in a Lean Premixed Methane/Air Charge using a Rapid Compression Expansion Machine," SAE Technical Paper 2012-01-0825, 2012, doi:10.4271/2012-01-0825.

21. Salaun, E., Apeloig, J., Grisch, F., Yvonnet, C.-E. et al., "Optical Investigation of Ignition Timing and Equivalence Ratio in Dual-Fuel CNG/Diesel Combustion," SAE Technical Paper 2016-01-0772, 2016, doi:10.4271/2016-01$\underline{0772 .}$.

22. Paykani, A., Kakaee, A.-H., Rahnama, P., and Reitz, R.D., "Progress and Recent Trends in Reactivity-Controlled Compression Ignition Engines," International Journal of Engine Research 17(5):481-524, 2015, doi:10.1177/1468087415593013.

23. Carlucci, A.P., Laforgia, D., Saracino, R., and Toto, G., "Study of Combustion Development in Methane-Diesel Dual Fuel Engines, Based on the Analysis of In-Cylinder Luminance," SAE Technical Paper 2010-01-1297, 2010, doi: 10.4271/2010-01-1297.

24. Nakamura, M., Ohashi, H., and others, "Study of Diesel Spray Combustion in an Ambient Gas Containing Hydrocarbon Using a Rapid Compression Machine," SAE Technical Paper 980899, 1997, doi:10.4271/980899.

25. Pickett, L.M., Kook, S., and Williams, T.C., "Visualization of Diesel Spray Penetration, Cool-Flame, Ignition, HighTemperature Combustion, and Soot Formation Using HighSpeed Imaging," SAE Int. J. Engines 2(1):439-459, 2009, doi: $10.4271 / 2009-01-0658$.

26. Idicheria, C.A. and Pickett, L.M., "Soot Formation in Diesel Combustion under High-EGR Conditions," SAE Technical Paper 2005-01-3834, 2005, doi:10.4271/2005-01-3834.

27. Manin, J., Pickett, L.M., and Skeen, S.A., “Two-Color Diffused Back-Illumination Imaging as a Diagnostic for Time-Resolved Soot Measurements in Reacting Sprays," SAE Int. J. Engines 6:1908-1921, 2013, doi:10.4271/2013-01-2548.

28. Westlye, F.R., Penney, K., Ivarsson, A., Pickett, L.M. et al., "Diffuse Back-Illumination Setup for High Temporally Resolved Extinction Imaging," Applied Optics 56(17):50285038, 2017, doi:10.1364/AO.56.005028.

29. Skeen, S., Manin, J., Pickett, L., Dalen, K. et al., "Quantitative Spatially Resolved Measurements of Total Radiation in High-Pressure Spray Flames," SAE Technical Paper 2014-011252, 2014, doi:10.4271/2014-01-1252.

30. Kook, S. and Pickett, L.M., "Soot Volume Fraction and Morphology of Conventional and Surrogate Jet Fuel Sprays at $1000-\mathrm{K}$ and 6.7-MPa Ambient Conditions," Proceedings of the Combustion Institute 33:2911-2918, 2011, doi:10.1016/j. proci.2010.05.073.

31. Pastor, J.V., Javier López, J., García, J.M., and Pastor, J.M., "A 1D Model for the Description of Mixing-Controlled Inert Diesel Sprays," Fuel 87(13):2871-2885, 2008, doi:10.1016/j. fuel.2008.04.017.

32. Schlatter, S., Schneider, B., Wright, Y.M., and Boulouchos, K., "Comparative Study of Ignition Systems for Lean Burn
Gas Engines in an Optically Accessible Rapid Compression Expansion Machine," SAE Technical Paper 2013-24-0112, 2013, doi:10.4271/2013-24-0112.

33. Kammermann, T., Koch, J., Wright, Y.M., Soltic, P. et al., "Generation of Turbulence in a RCEM towards Engine Relevant Conditions for Premixed Combustion Based on CFD and PIV Investigations," SAE Int. J. Engines 10(4), 2017, doi: 10.4271/2017-24-0043.

34. Skeen, S.A., Manin, J., and Pickett, L.M., "Simultaneous Formaldehyde PLIF and High-Speed schlieren Imaging for Ignition Visualization in High-Pressure Spray Flames," Proceedings of the Combustion Institute 35:3167-3174, 2015, doi:10.1016/j.proci.2014.06.040.

35. Bardi, M., Payri, R., Malbec, L.M.C., Bruneaux, G. et al., "Engine Combustion Network: Comparison of Spray Development, Vaporization, and Combustion in Different Combustion Vessels," 22(10):807-842, 2012, doi:10.1615/ AtomizSpr.2013005837.

36. Pickett, L.M., "Engine Combustion Network," http://www. sandia.gov/ecn/dieselSprayCombustion.php, 2013.

37. Musculus, M.P.B., "Measurements of the Influence of Soot Radiation on In-Cylinder Temperatures and Exhaust NOx in a Heavy-Duty DI Diesel Engine," SAE Technical Paper 200501-0925, 2005, doi:10.4271/2005-01-0925.

38. Gaydon, A.G., "The Spectroscopy of Flames," (Dordrecht, Springer, 1974).

39. Tautschnig, G., Hampel, B., Hirsch, C., and Sattelmayer, T., "Experimental Investigation of $\mathrm{OH}^{*}$ and $\mathrm{CH}^{*}$ Chemiluminescence Under Varying Operating Conditions," ASME Turbo Expo, Volume 1B: Combustion, Fuels and Emissions, 2013, doi:10.1115/GT2013-95850.

40. Hwang, W., Dec, J., and Sjöberg, M., "Spectroscopic and Chemical-Kinetic Analysis of the Phases of HCCI Autoignition and Combustion for Single- and two-Stage Ignition Fuels," Combustion and Flame 154(3):387-409, 2008, doi:10.1016/j.combustflame.2008.03.019.

41. Iijima, A. and Shoji, H., "A Study of HCCI Combustion Characteristics Using Spectroscopic Techniques," SAE Technical Paper 2007-01-1886, 2007, doi:10.4271/2007-01$\underline{1886}$.

42. Musculus, M.P.B., Singh, S., and Reitz, R.D., "Gradient Effects on two-Color Soot Optical Pyrometry in a Heavy-Duty DI Diesel Engine," Combustion and Flame 153(1):216-227, 2008, doi:10.1016/j. combustflame.2007.10.023.

43. Desantes, J.M., Pastor, J.V., García-Oliver, J.M., and Pastor, J.M., "A 1D Model for the Description of Mixing-Controlled Reacting Diesel Sprays," Combustion and Flame 156(1):234249, 2009, doi:10.1016/j.combustflame.2008.10.008.

44. Pastor, J.V., Payri, R., Garcia-Oliver, J.M., and Nerva, J.-G., "Schlieren Measurements of the ECN-Spray a Penetration under Inert and Reacting Conditions," SAE Technical Paper 2012-01-0456, 2012, doi:10.4271/2012-01-0456.

45. Pastor, J.V., Garcia-Oliver, J.M., Pastor, J.M., and VeraTudela, W., "One-Dimensional Diesel Spray Modeling of Multicomponent Fuels,” 25(6):485-517, 2015, doi:10.1615/ AtomizSpr.2014010370.

46. Schlichting, H. and Gersten, K., "Boundary-Layer Theory," (Berlin, Springer Heidelberg, 2016). 
47. Idicheria, C.A. and Pickett, L.M., "Ignition, Soot Formation, and End-of-Combustion Transients in Diesel Combustion under High-EGR Conditions," International Journal of Engine Research 12(4):376-392, 2011, doi:10.1177/1468087411399505.

48. Musculus, M.P. and Kattke, K., "Entrainment Waves in Diesel Jets," SAE Int. J. Engines 2:1170-1193, 2009, doi:10.4271/2009-01-1355.

49. Saito, H., Sakurai, T., Sakonji, T., Hirashima, T. et al., "Study on Lean Burn Gas Engine Using Pilot Oil as the Ignition Source," SAE Technical Paper 2001-01-0143, 2001, doi:10.4271/2001-01-0143.

50. Yeo, J., Rochussen, J., and Kirchen, P., “Application of an in-Cylinder Local Infrared Absorption Fuel Concentration Sensor in a Diesel-Ignited Dual-Fuel Engine," SAE International, 2016, doi:10.4271/2016-01-2310.

51. Weissman, M. and Benson, S.W., "Mechanism of Soot Initiation in Methane Systems," Progress in Energy and Combustion Science 15(4):273-285, 1989, doi:10.1016/0360$\underline{1285(89) 90016-6 .}$.

52. Sarathy, S.M., Westbrook, C.K., Mehl, M., Pitz, W.J. et al., "Comprehensive Chemical Kinetic Modeling of the Oxidation of 2-Methylalkanes from C7 to C20," Combustion and Flame 158:2338-2357, 2011, doi:10.1016/j. combustflame.2011.05.007.

53. Kamimoto, T., Uchida, N., Aizawa, T., Kondo, K. et al., "Diesel Flame Imaging and Quantitative Analysis of inCylinder Soot Oxidation," International Journal of Engine Research 18(5-6):422-435, 2016, doi: $10.1177 / 1468087416629282$.

54. Skeen, S.A., Manin, J., Dalen, K., and Pickett, L.M. "Extinction-Based Imaging of Soot Processes Over a Range of Diesel Operating Conditions," 8th US National Combustion Meeting, 2013.

55. Lee, D. and Hochgreb, S., "Rapid Compression Machines: Heat Transfer and Suppression of Corner Vortex," Combustion and Flame 114(3):531-545, 1998, doi:10.1016/S0010-2180(97)00327-1.

56. Mederer, T., Wensing, M., and Leipertz, A., "GE2-2 LaserInduced Fluorescence to Visualize Gas Mixture Formation in an Optically Accessible Hydrogen Engine(GE: Gas Engine,General Session Papers)," The Proceedings of the International Symposium on Diagnostics and Modeling of Combustion in Internal Combustion Engines 2012(8):374-379, 2012, doi:10.1299/jmsesdm.2012.8.374.

\section{Contact Information}

\section{Acknowledgments}

The authors would like to thank T. Kammermann and Dr. B. Schneider for the support using the RCEM and fruitful discussions. M. Decostérd and D. Erne technically assisted this work. Financial support from CCEM (project \#803: ScheDual), Research Association for Combustion Engines (FVV) and Swiss Federal Office of Energy (contract SI/501123-01) is gratefully acknowledged.

\section{Definitions/Abbreviations}

1D/2D/3D - 1/2/3 - dimensional

BDC - Bottom Dead Center

CR - Compression Ratio

DBI - Diffuse Back-Illumination

ET - (Pilot injector) Energizing Time

EOI - End of Injection

FoV - Field of View

FWHM - Full-Width at Half-Maximum

$\phi$ - Fuel/air equivalence ratio

$\phi_{\mathrm{CH} 4}$ - Methane/air equivalence ratio

$\phi_{\mathrm{n}-\mathrm{C12}}$ - Pilot fuel equivalence ratio

LIF - Laser Induced Fluorescence

HACA - Hydrogen Abstraction Carbon/acetylene Addition mechanism

HCCI - Homogeneous Charge Compression Ignition

HSC - High-Speed Camera

NIR - Near InfraRed

$\mathbf{O H}^{*}$ - Excited state hydroxyl radical

PIV - Particle Image Velocimetry

$\mathbf{P}_{\text {sol }}$ - Pressure at start of injection

RCEM - Rapid Compression-Expansion Machine

SOI - Start of Injection

$\mathbf{T}_{\mathbf{a d}}$ - Adiabatic flame temperature

$\mathbf{T}_{\text {s-app }}$ - Apparent soot Temperature

$\mathbf{T}_{\text {soI }}$ - Temperature at start of injection

UHC - Unburnt Hydrocarbons

TDC - Top Dead Center

UV - UltraViolet radiation

\section{Aleš Srna}

Paul Scherrer Institute

OVGA 119/A

CH-5232 Villigen PSI

Switzerland

ales.srna@psi.ch

https://www.psi.ch/ltv/ 


\section{Appendix A: Methane Mixture Distribution in the RCEM before Compression}

The methane mixture distribution in the RCEM prior to compression has been assessed using a specially designed test setup (Figure 18). The setup reproduces the cylinder head geometry of the RCEM with the piston in the BDC and provides optical access along the whole length of the cylinder via using a fused silica cylinder (inner diameter: $84 \mathrm{~mm}$ ). The aluminum covers were anodized to suppress the scattering of the laser sheet. One cover provides inlet and outlet ports for gas exchange as well as the methane admittance via the $\mathrm{CH}_{4}$ injector - which is mounted at the same position as in the RCEM (37.5 mm of the cylinder axes). The second cover holds a sapphire window for the purpose of illumination with laser. To reproduce the thermodynamic conditions in the RCEM, both covers are electrically heated. The heating of the quartz cylinder has been realized by heated gas circulation inside and outside of the cylinder.

The setup ensured equivalent charge conditions as in the RCEM prior to compression (pressure, temperature). Methane at a pressure of 60 bar has been doped with a $0.11 \%$ molar concentration of anisole $\left(\mathrm{C}_{6} \mathrm{H}_{5} \mathrm{OCH}_{3}\right)$ by using a heated bubbler system. The very low concentration of the dopant has been used in order to insure same flow characteristics through the injector as with pure methane. The dopant in the methane has been excited using the $266 \mathrm{~nm} 4$ th harmonic of a Nd:YAG laser (Quantel YG581C) with laser sheet dimensions of $84 \mathrm{~mm}$ $\mathrm{x} 1 \mathrm{~mm}$ and a pulse energy of approximately $18 \mathrm{~mJ}$ at $10 \mathrm{~Hz}$ repetition rate. The LIF signal of the dopant has been acquired with an ICCD camera (PCO DiCam Pro, S20 photocathode, $500 \mathrm{~ns}$ gate) using a Sodern $45 \mathrm{~mm} \mathrm{f} / 1.8 \mathrm{UV}$ imaging lens and a bandpass filter around $285 \mathrm{~nm}$ - $340 \mathrm{~nm}$ (Schott DUG11). Laser synchronization with the camera and the gas injector has been achieved using a combination of pulse and delay generators. A sequence in time up to $5 \mathrm{~s}$ duration after start of injection has been recorded and resolved with 50 images in this time. This does not allow a temporal resolution of the jet evolution during the injection itself (injection duration of $30 \mathrm{~ms}$ ). However, the jet mixing is expected to be a rather slow

FIGURE 18 Geometry of the test setup for the characterization of the methane distribution in the RCEM prior to compression

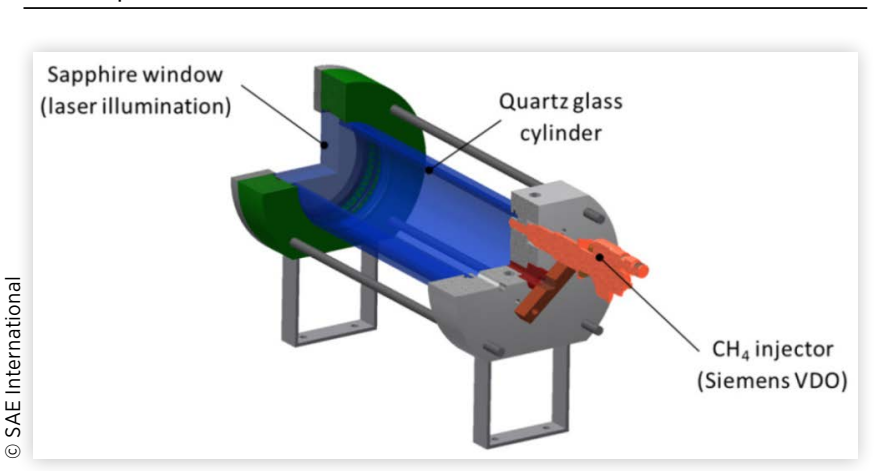

(c) 2018 SAE International. All Rights Reserved. process and therefore, the $10 \mathrm{~Hz}$ record rate sufficiently resolves the gas plume evolution at later time instances.

The applied detection system allowed for qualitatively good imaging of the methane mixing process from the SOI up to late in the mixing process ( $5 \mathrm{~s}$ after SOI). Figure 19 shows single shot evolution of methane concentration field for six select times after the SOI ranging from $5 \mathrm{~ms}$ to $4 \mathrm{~s}$ after SOI. During the injection as well as shortly afterwards the high momentum of the injected gas provides a rapid penetration of the gas plume. However, the momentum quickly dissipates after EOI and the gas plume needs up to $0.5 \mathrm{~s}$ to reach the opposite end of the glass cylinder. The asymmetric injector mount location results in deformation of the axially-symmetrical hollow cone injector's plume which forms an asymmetric penetration and distribution of the gas plume shortly after injection. The remaining large vortices provide further mixing after EOI; and by the time of $4 \mathrm{~s}$ after SOI, a high homogeneity of the tracer concentration is achieved.

The white field correction has been performed by creating a flow of tracer-seeded nitrogen through the cylinder and the image deformation due to the curved cylinder has been corrected accordingly. The extent of the remaining inhomogeneity has been investigated by calculating the mean concentration field at a time of $4 \mathrm{~s}$ after SOI (Figure 20) and by plotting the histogram of the deviation of single shots from the homogeneous tracer concentration (Figure 21). The mean tracer concentration field shows a repeatable slight inhomogeneity with larger gas concentration on the injector side of the cylinder. The range of this inhomogeneity is less than $10 \%$ from the homogeneous concentration. Single shot images reveal a higher range of inhomogeneity and standard

FIGURE 19 Single shot mixing evolution for 6 times after SOI ( 5 ms, 100 ms, 200 ms, 500 ms, 1500 ms, 4000 ms) normalized to the homogeneous concentration signal.

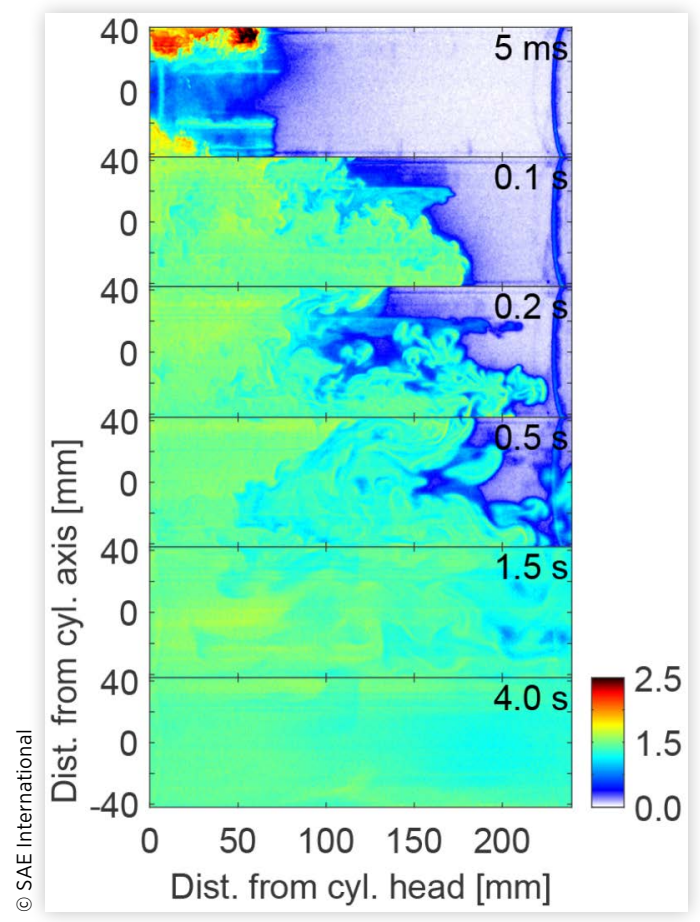


FIGURE 20 Average (50 repetitions) distribution of methane $4 \mathrm{~s}$ after injection, normalized with a fully homogeneous concentration.

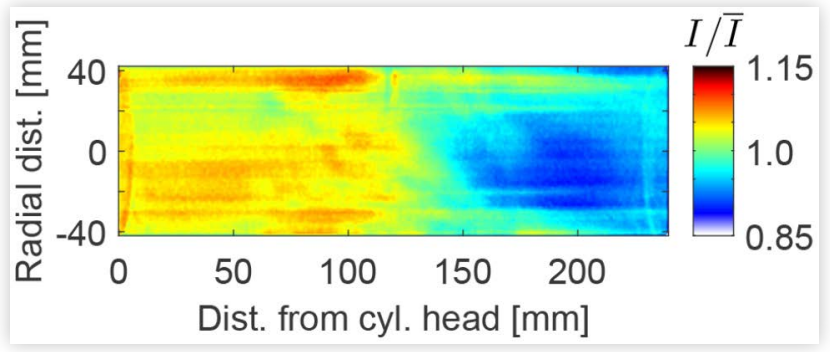

FIGURE 21 Histogram of detected methane concentrations at a time $4 \mathrm{~s}$ after SOI, normalized to fully homogeneous concentration. Red line indicated the standard deviation of the histogram $(\sigma=0.068)$

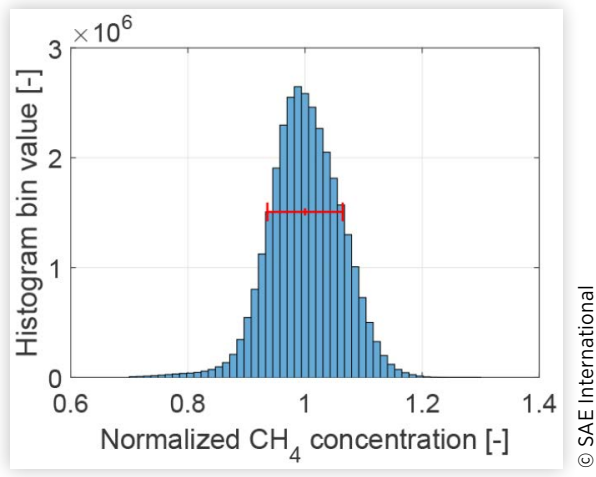

deviation of the distribution equals $\sigma=0.068$. This means that the inhomogeneity does not exceed $15 \%$ in $95 \%$ of the cylinder volume. In the actual RCEM, due to additional mixing during the rapid compression (wall-shedding vortex [55]), the inhomogeneity will be lower than in the glass cylinder setup.

This overall inhomogeneity of the methane distribution in the RCEM might be higher than in dual-fuel engines with port fuel injection but is smaller than in typical engines with direct fuel injection [56]. The inhomogeneity might influence the laminar flame speed in different parts of the cylinder and therefore exhibit some influence on the heat release rate during the premixed flame propagation. The influence of the inhomogeneity on the ignition delay is not expected to have a significant contribution, which has been confirmed by the very small variability of the ignition delay observed during the experiments (Figure 7). The influence of the remaining inhomogeneity on the sooting behavior of the combustion will be considerably smaller than due to the experimental variation of the methane concentration itself.

\section{Appendix B: 1D-Spectroscopy System Calibration}

The spectrum acquired by the setup depends on the quantum efficiency of the intensifier photo-cathode, vignetting effects of the relay optics coupling of the camera and intensifier, UV-lens transmission, grating and mirror efficiency of the spectrograph, and reflectivity of the beam-splitter dichroic mirror used to separate the DBI illumination light from the natural luminosity (Figure 22). Manufacturer data has been assumed for the quantum efficiency of all components except the beam-splitter optics. The spectral dependence of the beamsplitter reflectivity has been measured using a spectrograph and a broadband light source. The UV-lens manufacturer data for transmission at $400 \mathrm{~nm}$ has been used. The lens transmission at longer wavelengths has been estimated relative to the transmission at $400 \mathrm{~nm}$ using a setup with a spectrograph and a broadband light source in a similar fashion as the transmission of the beam-splitter has been determined. The efficiency of all elements has been multiplied together and used to correct the raw emission spectra detected by the camera.

FIGURE 22 Optical and quantum efficiency of the relevant elements in the 1D-spectroscopy optical path.

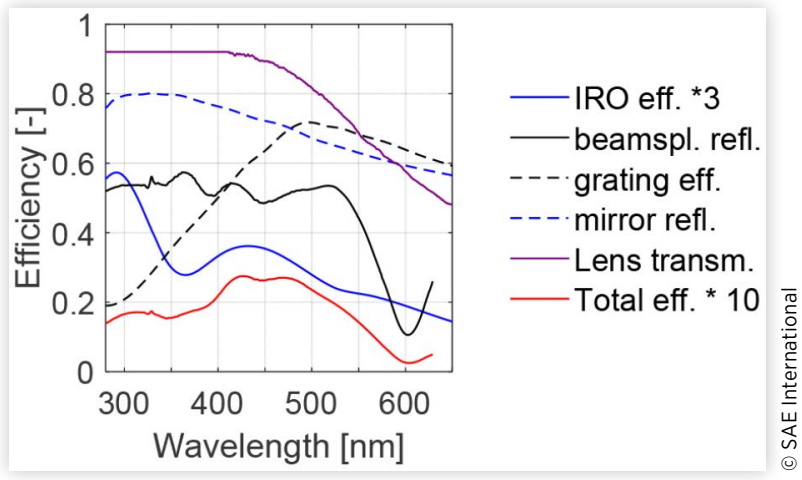

All rights reserved. No part of this publication may be reproduced, stored in a retrieval system, or transmitted, in any form or by any means, electronic, mechanical, photocopying, recording, or otherwise, without the prior written permission of the copyright holder. 